NASA Technical Memorandum 4415

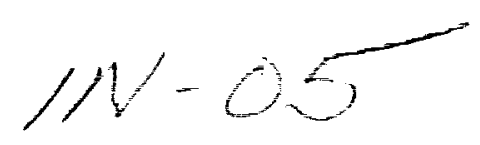

Flight Test Results From

a Supercritical Mission

Adaptive Wing With

Smooth Variable Camber

Sheryll Goecke Powers, Lannie D. Webb, Edward L. Friend, and William A. Lokos

NOVEMBER 1992

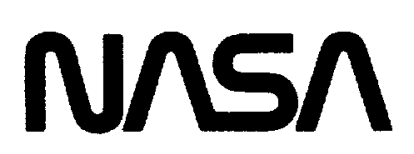




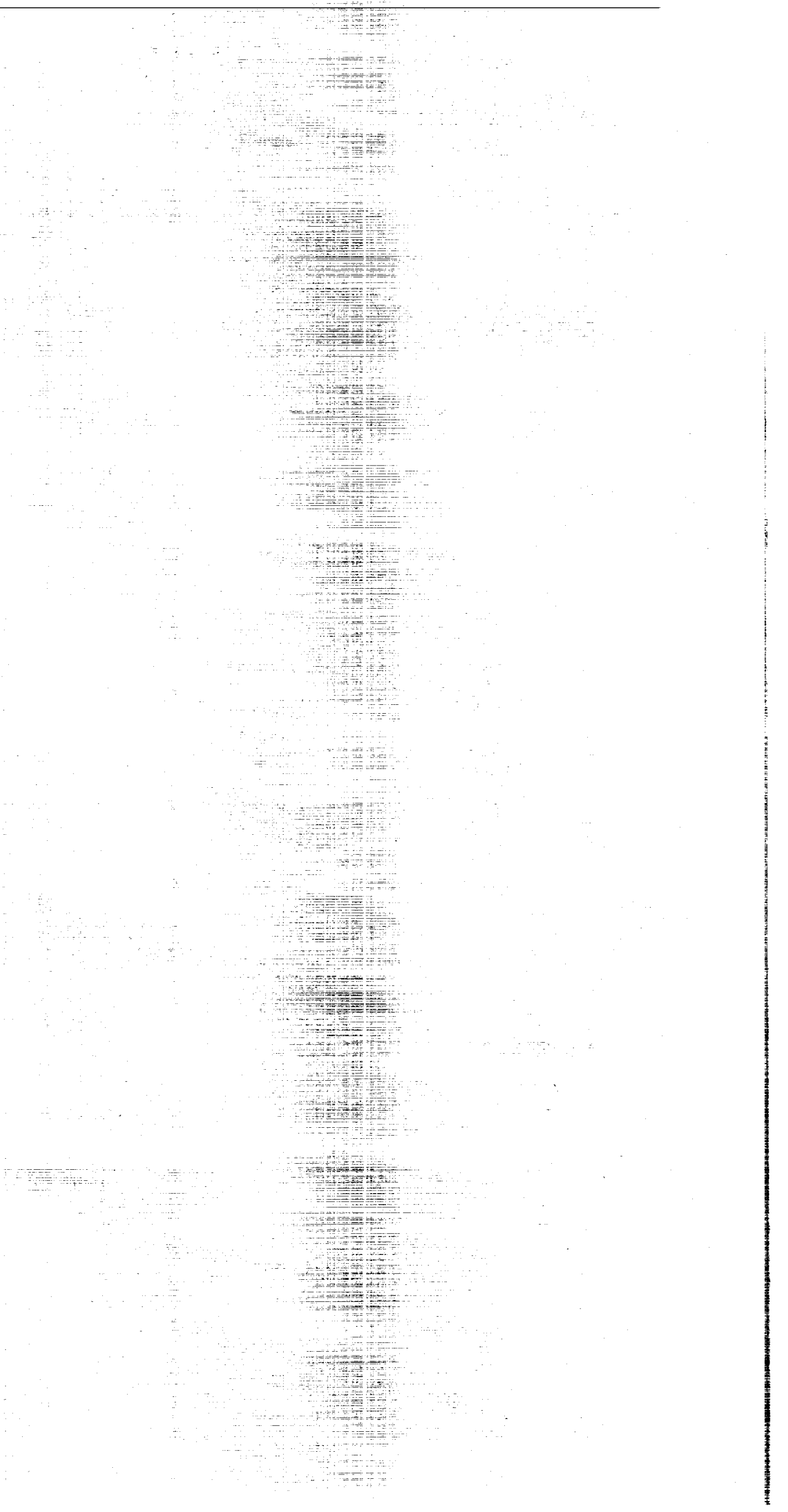


NASA Technical Memorandum 4415

\section{Flight Test Results From a Supercritical Mission Adaptive Wing With Smooth Variable Camber}

Sheryll Goecke Powers, Lannie D. Webb, Edward L. Friend, and William A. Lokos Dryden Flight Research Facility Edwards, California

National Aeronautics anc Space Administration

Office of Management Scientific and Technical Information Program

1992

(NASA-TM-4415) FLIGHT TEST RESULTS FROM A SUPERCPITICAL MISSION ATAOTIVE WING WITH SMOOTH VARIARLE CAMCR (NASA) 310
}

N93-11863

Uncl as

$H 1 / 05 \quad 0126295$ 


\title{
FLIGHT TEST RESULTS FROM A SUPERCRITICAL MISSION ADAPTIVE WING WITH SMOOTH VARIABLE CAMBER
}

\author{
Sheryll Goecke Powers* \\ I, annie I). Webb* \\ Edward L. Friend** \\ William $\Lambda$. Lokos** \\ NASA Dryden Flight Research Facility \\ Edwards, California
}

\begin{abstract}
The mission adaptive wing (MAW) consisted of leading- and trailing-edge variable-camber surfaces that could be deflected in flight to provide a near-ideal wing camber shape for any flight condition. 'These surfaces featured smooth, flexible upper surfaces and fully enclosed lower surfaces, distinguishing them from conventional flaps that have discontinuous surfaces and exposed or semiexposed mechanisms. Camber shape was controlled by either a manual or automatic flight control system. The wing and aircraft were extensively instrumented to evaluate the local flow characteristics and the total aircraft performance. This paper discusses the interrelationships between the wing pressure, buffet, boundary-layer and flight deflection measurement system analyses and describes the flight maneuvers used to obtain the data. The results are for a wing sweep of $26^{\circ}$, a Mach number of 0.85 , leadingand trailing-edge cambers $\left(\delta_{L E / T F}\right)$ of $0 / 2$ and $5 / 10$, and angles of attack from $3.0^{\circ}$ to $14.0^{\circ}$. For the wellbehaved flow of the $\delta_{L E / T E}=0 / 2$ camber, a typical cruise camber shape, the local and global data are in good agreernent with respect to the flow propertics of the wing. For the $\delta_{L E / T E}=5 / 10$ camber, a maneuvering camber shape, the local and global data have similar trends and conchusions, but not the clear-cut agreement observed for cruise camber.
\end{abstract}

\section{Nomenclature}

Reference values in brackets, [1, based on a trapezoidal planform at a leading-edge sweepback angle of $26^{\circ}$ scaled up, from Ref. 17.

\footnotetext{
*Aerospace Engineer. Member AIAA.

**Aerospace Engineer.

Copyright (C 1992 by the American Institute of Aeronautics and Astronautics, Inc. No copyright is asserted in the United States under Title 17, U.S. Code. The U.S. Government has a royalty-free license to exercise all rights under the copyright claimed herein for Governmental purposes. All other rights are reserved by the copyright owner.
}

AFTI advanced fighter technology integration

$a_{n_{c a}} \quad$ normal acceleration at center of gravity, $g$

$a_{n_{\text {: } t p t}}$ normal accoleration at cockpit, $g$

$a_{n H T}$ normal acceleration at horizontal tail, g

$a_{n w T} \quad$ normal acceleration at wingtip, g

BHR buffet intensity rise

$b \quad$ wing span, $\mathrm{ft}[56.55 \mathrm{ft}]$

$C_{N_{A}}$ airplane normal-force coefficient, $\left(a_{n_{c g}} W\right) / q_{\infty} S$

$C_{p} \quad$ pressure coefficient, $\left(p-p_{\infty}\right) / q_{\infty}$

$C_{\text {pet }}$ pressure coefficient on wing upper-surface at $x / c=0.96$

c streamwise local chord, ft

$c_{a v} \quad$ mean geometric chord, $\mathrm{ft}, S / b[11.0 \mathrm{ft}]$

$c_{M A C}$ mean aerodynamic chord, $\mathrm{ft}, 2 / S \int_{0}^{b / 2} c^{2} d y$

$[11.2 \mathrm{ft}]$

$c_{n} \quad$ section normal-force coeflicient, $\int_{0}^{1} \Delta C_{p} d x / c$

FDMS flight deflection measurment system

MAW mission adaptive wing

$M_{\infty} \quad$ free-strearn Mach number

PCM pulse code modulation

$p \quad$ local wing surface static pressure, $\mathrm{lb} / \mathrm{ft}^{2}$

$p_{\infty} \quad$ free-stream static pressure, $\mathrm{lb} / \mathrm{ft}^{2}$

$q_{\infty} \quad$ free-stream dynamic pressure, $\mathrm{lb} / \mathrm{ft}^{2}$

rms root mean square

$S \quad$ wing reference area, $\mathrm{ft}^{2}\left[622.0 \mathrm{ft}^{2}\right]$

TACT transonic aircraft technology

$U$ local flow velocity in the boundary layer, $\{\mathrm{t} / \mathrm{sec}$

$U_{c} \quad$ local flow velocity at $Y=5 \mathrm{in}$., $\mathrm{ft} / \mathrm{sec}$

$W$ airplane weight, $1 \mathrm{~b}$ 


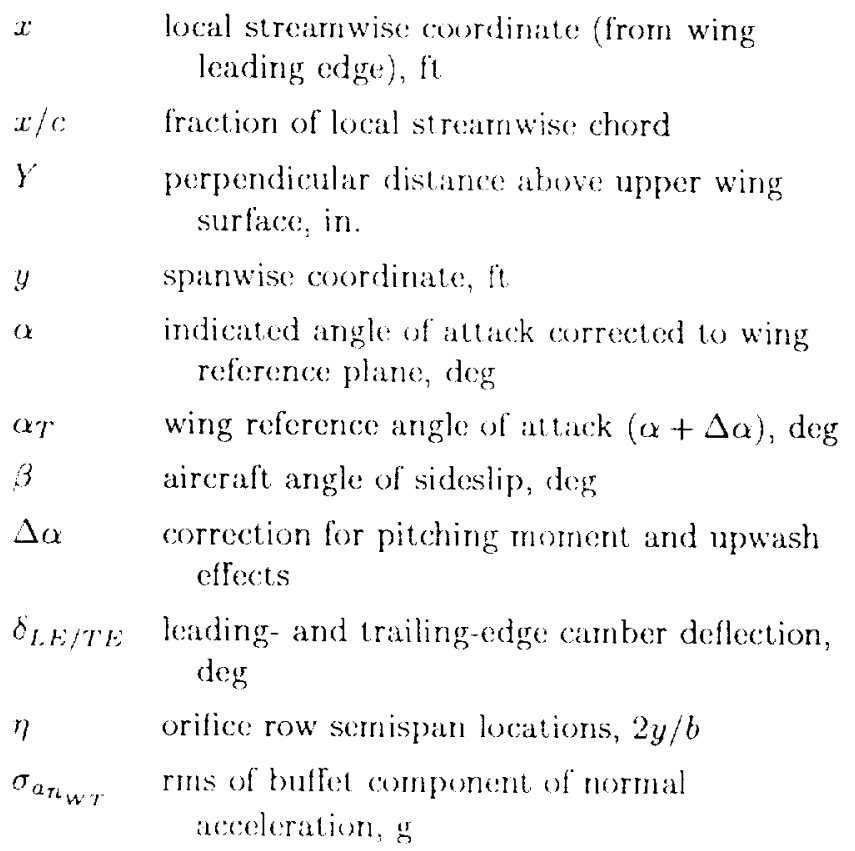

\section{Introduction}

A wing configuration that would allow smooth camber changes throughout the flight envelope can provide additional acrodynamic performance at all flight conditions. Variable camber alone has been a proven concept for enhancing maneuveratility for noarly all flight conditions. ${ }^{\prime}$ On airplanes such as the F-16 and $F-18$ aircraft the variable camber is achieved through discrete flap positions. Better performance can be achieved with smooth variable camber. Design studies ${ }^{2,3}$ to develop a smooth, variable-camber supercritical wing resulted in the mission adaptive wing (MAW). The MAW consisted of leading-and trailingedge variable-camber surfaces that can be deflected in flight to provide a near-ideal wing camber shape for any flight condition. These variable-camber surfaces featured smooth, flexible upper surfaces and fully enclosed lower surfaces, distinguishing them from conventional flaps that have discontinuous surfiaces and exposed or semiexposed mechanisms. The camber shape was controlled by either a manual or antomalic flight control system. ${ }^{1}$

The wing and the aircraft were extensively instrumented ${ }^{5,6}$ to evaluate the aerodymamic performance of the $\mathrm{MAW}$. Instrumertation located on the MAW included orifices lor surface pressures, a boundary-layer rake, a flight deflection measurement syslem (I) J MS), winglip accelerometers, strain gages, and control position transducers.

Results from the MAW Program were summarized at the final symposium held at the NASA I)rydern
Flight Research Facility in April 1989. ${ }^{7}$ Aerodynamic characteristics and performance evaluations, for example wing pressure, buffet, and lift and drag test results, also have been discussed in separate subdiscipline reports. ${ }^{8-11}$ The data indicate that the advanced fighter technology integration ( $\mathrm{FT} \mathrm{F}$ )/F-111 MAW aircraft had significantly improved aerodynamic characteristics, compared to the the basic $\mathrm{F}-111 \mathrm{~A}$ and transonic aircraft technology (TACT) designs.

This paper provides a correlation of the multidisciplines, showing how the interrelationships from the wing pressure, buffet, boundary-layer and FDMS anal$y$ ses strengthen and support each other. Also included are descriptions of the flight maneuvers used to obtain the data. The results are for a wing sweep of $26^{\circ}$, a Mach number of 0.85 , leading- and trailing-edge cambers $\left(\delta_{L E / T E}\right)$ of $0 / 2$ and $5 / 10$, and angles of attack from $3.0^{\circ}$ to $14.0^{\circ}$. The data presented are for dynamic pressures of 300 and $600 \mathrm{lb} / \mathrm{ft}^{2}$ with the majority of the data shown being at $300 \mathrm{lb} / \mathrm{ft}^{2}$.

\section{Background}

The last research program conducted on the $A F T / F-111$ research aircraft was the testing of the MAW concept. The AFTI/F-111 MAW aircraft was initially an $\mathrm{F}-111 \mathrm{~A}$ airplane, which was modified for use in the F-111 TAC' Program. ${ }^{12,13}$ The original design of the F-111 aircraft used a variable-sweep wing to increase the number of optimum flight conditions. The TAC' Program combined is supercritical airfoil ${ }^{14}$ with planform and twist changes to improve transonic cruise and mareuver performance relative to the conventional l'-111 wing. ${ }^{15,16}$ The MAW Program used a smooth, variable-camber supercritical wing to provide high levels of aerodynamic efficiency over a range of subsonic, transonic, and supersonic flight conditions. Previous supercritical wing designs tended toward a fixed geonetry shape that was a compronise for specific mission requirements. The MAW minimized penalties for off-design flight conditions through the combination of smooth-skin variathle camber and variable sweep.

Maintaining an elficient airfoil shape by the use of camber sethings was one of the basic design goals. The flight program provided adequate instrumentation to allow evaluation of this complex design.

Correlation of the buffet characteristics with the wing pressure distributions adds to the technical interpretation of the data. Boundary-layer data at the wing trailing edge support the buffet and pressure data with respect to separation. The wing deflection data provide a wing definition with load factor and angle of attack. The resulting in-flight deflections supplement the wing pressure diata. 


\section{Description of Airplane and Wing}

The $\Lambda \mathrm{FTl} / \mathrm{F}-111 \mathrm{M} A \mathrm{~W}$ airplane and the camber shape of the wing are shown in lig. 1. The airplane was initially an $1-111$ airplane with the wings replaced for the TACT/F-111 Program. "'2 'The "TACl wing, except for the wing box, was subsequently replaced with the MAW. Modifications ${ }^{18}$ were made to the TACT wing planform to accommodate installation of the smoothskin leading- and trailing-edge variable-camber systems. The wing design coordinates at a $26^{\circ}$ wing sweep for the $1-g$ cruise $\mathrm{MAW}$ with $\delta_{1, k / T}=0 / 2$, and the wing-splash coordinates at orifice row semispan location $(\eta)=0.76$ and $\delta_{L, F / T}=0 / 2$ are given in Ref. 19 . Selected MAW design coordinates and the corresponding coordinates from the 1/12-scale: wind-tunnel model are compared in Ref. 20. The variable-camber leadingand trailing-edge surfaces of the $M A W$ are illustrated in Fig. 1(b). Note that the positive dircetion is down.

\section{Instrumentation}

\section{Wing Pressure Orifices}

For this study, the pressure instrumentation was located on the right wirg of the $A F=I / F-111$ airplane (sec Fig. 2(a)). A detailed discussion of the static pressure instrumentation is found in Red. 21. There were 152 flush-surface static pressure orilices located on the upper and lower surfaces in four chordwise rows aligned with the free-strearn airfow at a leading-edge sweepback angle of $26^{\circ}$. The pressure orifices were spaced so that the closest spacing was in the midsection of the upper wing surface. The number of upper and lower orifices at each semispan station is presented in Fig. 2(a). Nine of the 10 pressure transducer boxes were located irside: the flexible leadingand trailing-edge flap surlaces. This required connecting the leading- and trailing-edge surfaces with a flexible fluorosilicon tubing (0.07-in. inside diameter). The orifices located on the surface of the wing box were connected by stainless steel tubing (0.12-in. inside diameter). In most cases the length of the pressure lines from the orifices to the transducers was linited to less than $5 \mathrm{ft}$, thus pressure lag effects were minimized. More details about the pressure orifices can be found in Ref. 19.

\section{Buffet Accelerometers}

Figure 2(a) shows the right wingtip locations for the high-frequency nommal accelerometers used in the buffet analysis. The locations for the cockpit, lelt wingtip and horizontal tail accelerometers are given in let. 9 . The accelerometers used only for the high-frequency analysis were filtered in the airplane instrumentation package to remove the low-lrequency maneuver component (for example, the wingtip and horizontal tail normal accoleromoters, $a_{\tau_{t}, T}$ and $a_{n_{n},}$, respectively).
Other accelerometers (such as the cockpit accelerometer, $\left.a_{n_{\text {tak }} t}\right)$ were filtered during the data analysis after the flight. Stability and control parameters and surface position indicators were also used in the buffet analysis.

\section{Boundary-Layer Rake}

The "12-probe" boundary-layer rake was installed on the upper wing surface at $\eta=0.76$ (see Fig. $2(\mathrm{a})$ ). The leading edge of the center probes was at $x / c \cong$ 0.96 , where $x$ is the streamwise coordinate and $c$ is the streamwise local chord. Three impact pressures were measured at each probe height. For 3 flights, 31 upper surface orifice transducers from rows $\eta=0.76$ and 0.59 and 5 spare wing transducers were connected instead to the boundary-layer rake shown in Fig. 2(b). Local flow direction was calculated using the pressures from the two side probes (cut at $45^{\circ}$ ) and the calibration technique described in Ref. 22. Because of transducer problems, the pressures at the perpendicular distance above the upper wing surface $(Y)=0.03 \mathrm{in}$. and $4.47 \mathrm{in}$. (see Fig. 2(b)) were not measured.

\section{Flight Deflection Measurement System}

The electro-optical FI)MS used in this study 6 was an updated version of a system used previously. ${ }^{23,24}$ The MAW FIMMS consisted of a control unit, a receiver, a target driver, and 13 infrared light-emitting diode targets (Fig, 2(c)). The targets were mounted on points of structural interest on the lower surface of the left wing. The receiver was mounted behind a window panel in the left side of the fuselage below the wing. From this receiver location all targets could be viewed for all camber settings when the wing was swept to $26^{\circ}$. The control unit and target driver were mounted on the right-hand instrumentation pallet located in what had been the woapons bay.

The PDMS control unit used the end-of-frame pulse from the pulse code modulation (PCM) system as a synchronization signal. The control unit would command the target driver to momentarily energize each target in order. Prior to the illumination of each target the control unit would initiate a sequence within the receiver. This sequence involved clearing its linear diode array, scanning the array to sample the background light signature and then scanning again with the target on. This process was necessary to accomplish the automatic background light compensation. The background light signal was used to modify the target light signal to improve system operating range and tolerance of ambient light. Each target data sample was transferred to the PCM system as two 10-bit digital words. One word contained target identification and error messages, while the other carried the target position data. References 6 and 25 provide more comprehensive information on the FDMS. 


\section{Aircraft Measurements}

Free-stream flight parameters, Mach number $\left(M_{\infty}\right)$, static pressure $\left(p_{\infty}\right)$, dynamic pressure $\left(q_{\infty}\right)$, and angle of attack $\left(\alpha, \alpha_{T}\right)$ and angle of sideslip $(\beta)$ were measured and derived from sensors installed on the AFTI/F-111 airdata boom. Mach number data from a modified MA-1 type uncompensated pitot-static probe ${ }^{26}$ were corrected for position error. Angle of attack and angle of sideslip were measured using a flightpath accelerometer vane system. ${ }^{27}$ Angle of attack is referenced to the wing reference plane for consistency with the wind-tunnel data. Because the noseboom is canted $2.5^{\circ}$-down relative to the vehicke body axis, and the MAW is set to an angle $1 .()^{\circ}$-up relative to the vehicle body axis, a $3.5^{\circ}$ correction was added to the indicated vane angle of attack to obtain the indicated angle of attack $(\alpha)$. This angle of attack was corrected for pitching moment and upwash effects ${ }^{10}$ to obtain $\alpha_{T}$. This corrected angle of attack was used for the wing pressure data analysis.

All the instrumented parameters wore recorded digitally on an airborne PCM system. The PCM system had a sampling rate of 20 to 800 samples/sec. Each wing surface and boundary-layer pressure was sampled at 20 samples/sec. Fach high-frequency accelerometer used for the buffet study was low-pass-filtered on the airplane at $160 \mathrm{IJ}$. The system sampling rate for the FDMS data channel was 200 samples/sec. This means that with the 13 FD.MS targets installed and 3 spare channels, each target was simpled 12.5 times a second.

\section{Analysis Techniques}

\section{Pressure Data}

The data used for the surface and boundary-layer pressures were choser from stabilized and quasistabilized flight conditions to minimize concerns ateout pressure and PCM sampling lay. When solecting datat for analysis, maximum deviations from the desired flight conditions for $M_{\infty}$ and $\alpha_{T}$ were 0.01 and $0.25^{\circ}$, respectively. For the boundary-layer data, the Mach number and velocity calculations used the assumptions (1) that the local static pressure was constant through the boundary layer and (2) that total temperature was constant through the boundary layer and equal to the free-stream value. The local static pressure was the surface static pressure at $x / c=0.96$ (directly ahead of the rake).

\section{FDMS Data}

The data used for the loms analysis were from lefthand turns, since this meant the left wing was down and looking at a darkened background (dark compared to the sky). The lefthand turn also avoided including the sun in the background. Nhthough not necessary, this provided an optimum working environment for the optical measurement system. Most of the data were obtained for stabilized or quasi-stabilized times because of concerns that spurious signals from the FD.MS could possibly affect the high-frequency response instrumentation.

\section{Buffet Data}

The buffet analysis primarily consists of determining the root mean square (rms) value of the buffet accelerations for increasing angles of attack. The low-frequency mancuver components for the wingtip accelerometer are filtered in the airplane instrumentation package, leaving only the high-frequency response. The rms values and power spectral density estimates were then computed. The fluctuating accelerations were analyzed for contimuous 1 -sec time segments during periods of increasing angle of attack. The rms value of the accelcrations for each continuous time segment are shown as buffet loads in the data figures. Power spectral density techniques indicate the power and frequency distribution of the buffet parameters. The natural frequencies of the primary structure for the wing and the frequencies obtained from the wingtip accelerometer analysis showed good agreement. This agreement lends confidence in the instrumentation installation and analysis techniques (see Ref. 28).

The buffet intensity rise was defined as the point where the rmis buffet component of normal acceleration $\left(\sigma_{a_{n_{w}}}\right)$ begins to increase rapidly with respect to increasing airplane normal-force coefficient $\left(C_{N_{A}}\right)$ (knee of $C_{N_{A}}$ as a function of $\sigma_{a_{n_{W}}}$ curve). This is discussed in a later section.

\section{Test Points}

Mlight datit presented in this paper are for a Mach number of 0.85 and a $3.0^{\circ}$ to $14.0^{\circ}$ angle-of-attack range. Frec-stream dynamic pressures were 300 and $600 \mathrm{lb} / \mathrm{ft}^{2}$, with most of the data being for $300 \mathrm{lb} / \mathrm{ft}^{2}$. In most cases, data were selected for analysis for angles of sideslip near $0^{\circ}$. Flight Reynolds number was approximately $2.3 \times 10^{6} \mathrm{ft}^{-1}\left(26 \times 10^{6}\right.$ based on the mean acrodynamic chord $\left.\left(c_{M A C}\right)=11.2 \mathrm{ft}\right)$.

\section{Test Maneuvers}

The diverse nature of the research objectives in this flight test program resulted in the use of several types of flight maneuvers. Wing pressures and boundary-layer proliles required slow controlled windup turns to minimize concerns regarding pressure and PCM system lag. The aircraft would be stabilized at the desired Mach number and altitude before entering the windup turn. During an ideal slow windup turn, the aircraft was stabilized for a few seconds or longer at each desired Mach number and angle-of-attack combination. Because of 
thrust limitions, it was not possible to hold altitude and Mach mumber constant at the higher angles of attack $\left(>8.0^{\circ}\right)$ and/or llap settings. Windup turns performed for bullet and loads measurements were at a higher turn rate because accelerometers and strain gages were not susceptible to pressure lag. The FDMS data were obtained during the pressure maneuvers to correlate the FI)MS and pressure data.

\section{Wing Pressure}

Figure 3 illustrates the slow windup-turn maneuver and the response of one pressure transducer and a wingtip accelerometer. During the initial portion of this particular mancuver, the pilot was adjusting altitude to achieve the desired conditions later in the maneuver. The initial part of the maneuver was unsteady in nature, but developed into a steady turn culminating at approximately 80 sec at the maximum airn angle-of-attack and dynamic pressure values, with the Mach number within acceptable limits (see $\Lambda$ nalysis Techniques section). The boundary-layer data and FI)MS data were gathered using this type of windup turn. Soon after reaching the desired conditions, the onset of separation is indicated by the traces for the wingtip accelerometer and the trailing-edge pressure orifice at $x / c=0.96$ and $\eta=0.93$; then the maneuver is lerminated.

\section{Buffet}

Figure 4 illustrates a windup-turn maneuver for the baseline configuration $\delta_{L E / T H}=0 / 2$. This was a typical windup-turn maneuver used for the buffet evaluation. This mancuver was started at trim and continued to maximum allowable angle of attack. Mach number was held nearly constant and altitude and dynamic pressure were sacrificed where available thrust was limited. As angle of attack is increased, there is a sudden increase in buffet (time $\approx 33$ sec, $\alpha \approx 10.0^{\circ}$ ), known as the buffet intensity rise (BIIR). This BIR for the wingtip is followed by initial buffet at the pilot's station (time $\approx 34$ sec). Next are the simultaneous onset of wing rock and BIR for the horizontal tail (time $\approx 38 \mathrm{sec}$ ). Buffet characteristics for the MAW are discussed in more detail in Ref. 9.

\section{Other Types of Maneuvers}

Pushover pullup ( $\mathrm{POP}^{\mathrm{C}}$ ) maneuvers were used to gather data for many of the tests points in the performance part of the program. This type of maneuver is usually rapid in nature but will keep the aircraft near the initial premaneuver flight conditions. It was generally not possible to pause and hold angle of attack. Another maneuver was the level accoleration used primarily for performance and evaluation of the automatic control modes. ${ }^{4}$ In addition, all the disciplines used data from any suitable maneuver, including the trim or specilied start conditions during the setup of data runs.

\section{Results And Discussion}

\section{Span Effects on Pressure Distribution}

In Fig. 5, the chordwise pressure coeflicient $\left(C_{p}\right)$ distributions as a function of $x / c$ are shown at the four semispan stations for $M_{\infty}=0.85, q_{\infty} \approx 300 \mathrm{lb} / \mathrm{ft}^{2}$, $\delta_{L E / T E}=0 / 2$ (baseline camber configuration), and for $\alpha_{T}=8.0^{\circ}$ and $10.0^{\circ}$. 'These two angles of attack were selected to show the effects of trailing-edge flow conditions on the pressure profiles. The $\alpha_{T}=8.0^{\circ}$ data have good presssure recovery at the trailing edge, and the midspan profiles are typical of supercritical airfoils ${ }^{3}$ at or near the wing design conditions. All the upper surface pressure profiles have a strong negative pressure peak at the leading edge; however, for the midspan rows $(\eta)=0.59$ and 0.76$)$ for $\alpha_{T}=8.0^{\circ}$ the peak is followed by nearly constant $C_{p}$ plateaus. For $\alpha_{T}=8.0^{\circ}$ the $C_{p}$ profiles "shock down" from approximately $x / c \cong 0.40$ at $\eta=0.93$ to $x / c \cong 0.70$ at $\eta=$ 0.40 . Following the aft shocks, the $C_{p}$ values indicate a region of recompression that continues to the trailing edge. At the trailing edge, the pressures show good recovery for all the semispan stations. The $C_{p}$ profiles for $\alpha_{T}=10.0^{\circ}$ also show strong leading-edge negative pressure peaks. The midspan $C_{y}$ plateaus have disappeared with the movernent of the aft shock forward consequent to the separation of the boundary layer at the trailing edge. The shading on the trailing edge of the wing represents an approximate region of separated flow determined by analysis of the chordwise $C_{p}$ profiles for $\alpha_{T}=10.0^{\circ}$.

Figure 6 illustrates the $C_{p}$ profiles for the same Mach number and angles of attack as Fig. 5 but for $\delta_{L E / T E}=5 / 10$. The leading-edge camber of $5^{\circ}$ produces a rounded leading-edge $C_{p}$ profile. The midspan $C_{p}$ profiles are semiflat, followed by att shock recompression near the trailing-edge-flap line $(x / c \cong 0.70)$. The wingtip row $(\eta=0.93)$ is similar except for the large negative pressure area aft of the flap line, followed by a large secondary velocity peak. As in Fig. 5, the aft shock has moved toward the leading edge as $\alpha_{T}$ increased to $10.0^{\circ}$. The larger trailing edge deflection angle and angle of attack, both $10.0^{\circ}$, combine to increase the approximate region of separated flow shown, which is indicated by the shided area.

\section{Angle-of-Attack Effects on Aft Shock Location}

Figure $7(a)$ shows the relationship with $\alpha_{T}$ of aft shock location (see Ref. 19 for discussion) along row $\eta=0.76$ for $M_{\infty}=0.85, q_{\infty} \approx 300 \mathrm{lb} / \mathrm{lt}^{2}$, and $\delta_{L A / T E}=0 / 2, \quad$ As angle of at.ack increases from $6.0^{\circ}$ to approximately $8.5^{\circ}$, the location moves from 
approximately 30 -percent $x / c$ to approximately 60 percent $x / c$. As angle of attack continues to increase, the shock location then begins moving forward again to approximately $30-$ percent $x / 0$ as $\alpha T$ increases to $11.0^{\circ}$. The windup-turn time history in fig. $7(b)$ illustrates the effect on the orifice pressures of alt shock movement over the upper surface of the wing for the same flight conditions shown in Fig. 7(a). In Fig. 7(b), absolute pressures from six representative locations are shown plotted as a function of time. One is from a wing orifice near the leading-edge area ( $x / c=9$ percent), four are from the midsection $(x / c=37,47,56$, and 59 percent) and one is near the trailing edge $(x / c=96$ percent). As angle of attack increases during the windup turn, the aft shock moves rearward over the orifices for the midchord pressures and reaches approximately 60 -percent $x / c$, then it retraces its movement forward. The traces in Fig. 7(b) show that as the alt shock moves rearward, lower orifice pressure is measured in a region between the strong negative pressure peak at the wing leading edge and the aft shock. The aft shock never reaches the trailing-edge orilice $(x / c=96$ percent $)$ but there are indications of disturbed flow for $\alpha_{T}>9.0^{\circ}$, which can be noted by a high-frequency content in the pressure traces between the aft shock and the trailing edge. This may result from disturbances at the base of the aft shock and from the beginning of trailing-edge separation, ${ }^{29}$

Figures $7(c)$ and (d) present a detailed comparison of two windup-turn time histories at $M_{\infty} \approx 0.85$ showing pressure traces for all four trailing-edge orifices and their associated traces of angles of attack and wingtip accolometers for $\delta_{L E / T H}=0 / 2$ and $5 / 10$. In attached flow at the trailing edge, the flow should recover to the free-stream static pressure, but a decreasing pressure indicates nonrecovery to free-stream static pressure and separated flow at the trailing edge. In Fig. $7(c)$ for $\delta_{L E / T E}=0 / 2$ the trailing-edge traces are smooth until approximately $9.0^{\circ}$ angle of attack. Beyond this angle of attack, three of the four pressures $(\eta=0.76,0.59$, and 0.40$)$ break toward lower pressure values producing an indication of trailing-edge separation. The wingtip accelerometer trace, $a_{n w w}$, also closely correlates with the trailing-edge pressures, both fluctuating (time $>60 \mathrm{sec}$ ) with small changes in angle of attack. For $\delta_{L E / T E}=5 / 10$ (lig. $7(d)$ ), the two midwing trailing-edge pressures $(\eta)=0.76$ and 0.59$)$ have a pronounced break to a lower pressure near $\alpha=8.0^{\circ}$. As the windup turn continues (time $>100 \mathrm{sec}$ ), the aircraft begins to lose altitude rapidly because of the highor drag from the larger llap sctlings (the altitude trace is not shown). This results in the higher pressures observed for all four trailing-edge pressures. The $a_{n w T}$ trace indicates an increased level of activity (see Fig. $7(d)$ ) compared with the $\delta_{L H / T}:=0 / 2$ case over the entire windup turn. This residual buffet "buzz" has been shown to be associated with the larger flap settings. ${ }^{9}$ Aso appearing (for time $>110 \mathrm{sec}$ ) in the $a_{n_{w}}$ trace and the trailing-edge pressure traces of rows $\eta=0.93$ and 0.10 are flucuations that are a function of the variations in angle of attack.

\section{Wingtip Twist Effects}

The incremental change in wingtip twist caused by load (wingtip delta twist) was calculated as the difference between the changes in deflections of the forward and aft wingtip targets. This wingtip delta twist is the incremental twist caused by load, not the total twist. The wingtip delta twist, in degrees, is shown in Fig. $8(a)$ as a function of free-stream dynamic pressure for three camber settings at $M_{\infty}=0.85$. The trailing-edge-up twist is negative. The close agreement between the data for $\delta_{L E / T E}=0 / 2$ and $10 / 2$ show that the effect of leading-edge camber on wingtip twist is insignificant compared to that of trailing-edge camber. The FlEXSTAB predictions reported in Ref. 30 show the same trend. Only one data point was available for $\delta_{L E / T E}=5 / 10$ at $q_{\infty} \approx 600 \mathrm{lb} / \mathrm{ft}^{2}$. The vertical spread in the groups of measured wingtip twists is caused by the variation in aircraft angle of attack. For a given dyramic pressure and Mach number, an increase in angle of attack causes a corresponding increase in load fuctor, which in turn directly affects the wingtip delta twist. Thus, increasing aircraft angle of attack causes more negative wingtip twist, which is also referred to as "washout". The resulting local angle of attack that the wingtip experiences is therefore less than the aircraft angle of attack for a positive normal acceleration maneuver. This wingtip washout may explain why the wingtip pressure traces $(\eta=0.93)$ in Figs. $7(c)$ and (d) dilfer in the separation indicated. In Fig. 7 (c) a washout of $1.5^{\circ}$ or larger could delay separation enough to show little, if any, effect. But in Fig. 7(d) the $10^{\circ}$ trailing-edge flap plus the angle of attack of the windup turn would be large enough to overcome any washout indicated in Fig. 8(a) for $\delta_{L E / T E}=5 / 10$. Thus, the wingtip pressure trace indicates trailing-edge separation.

Figures $8(\mathrm{~b})$ and (c) compare wing surface pressure profiles at two span locations $(\eta=0.93$ and 0.76$)$ at $M_{\infty}=0.85, \alpha_{T}=8.0^{\circ}, \delta_{L E / T E}=0 / 2$, and $q_{\infty} \approx$ 300 and $600 \mathrm{lb} / \mathrm{ft}^{2}$. In the figures, the wingtip twist effects, if any, are minimal at the inboard row location while the outboard row shows only a small difference in the wingtip delta twist for the two dynamic pressures. The wingtip delta twist is only $0.5^{\circ}$ for $\delta_{L E / T E}=0 / 2$, which would suggest that large effects would not be anticipated for the two dynamic pressures investigated.

\section{Buffet Intensity}

Figure 9 presents the normal-force and buffet intensity characteristics for the baseline configuration, 
$\delta_{L E / T E}=0 / 2$, and for the $\delta_{L E / T E}=5 / 10$ configuration. The $\delta_{L F / T E}=5 / 10$ configuration is regarded as one of the better fixed-flap configurations for transonic maneuvering. ${ }^{31}$ The nomal-force curves for the $\delta_{L E / T E}=0 / 2$ and $5 / 10$ configurations have breaks that imply the presence of signilicant areas of llow separation on the wing. These treaks oceur at a $C_{N_{A}} \approx 0.80$ and $\alpha=9.5^{\circ}$ for the $\delta_{L L / T E}=0 / 2$ configuration (Fig. $9(a)$ ), and at a $C_{N_{A}} \approx 1.00$ and $\alpha \approx 10.3^{\circ}$ for the $\delta_{L E / T E}=5 / 10$ configuration (Fig. $\left.9(\mathrm{~b})\right)$ ). 'The difference in the $C_{N_{A}}$ values at the normal-force break (approximately $0.20 C_{N_{A}}$ ) indicates the influence of the wing trailing-edge deflection on the coeflicient data.

The buffet intensity data $\left(C_{N_{A}}\right.$ as a function of $\left.\sigma_{a_{n_{w} T}}\right)$ indicate slightly lower BIR values in terms of $C_{N_{A}}$ than the normal-force-break data. Similar improvernents in the BIR and the intensity characteristics are shown for the $\delta_{L E / T E}=5 / 10$ configuration, with respect to the normal-force curves. However, for the $\delta_{L E / T E}=5 / 10$ configuration and low $C_{N_{A}}$ values, the intensity data $\left(\sigma_{a_{n} w}\right)$ indicate a large offset when compared with the $\delta_{L, F T H}=0 / 2$ data. This offset indicates a low-level separation occurring before the BIR with a maximum value of $\sigma_{o n_{w}} \approx 0.25$. A similiar comparison for the $\delta_{L E / T E}=0 / 2$ configuration indicates a $\sigma_{a_{n_{W T}}} \approx 0.06$. The offsets are pointed out in Fig. 9.

\section{Summary of Pressurc and Buffet Characteristics}

In Fig. 10, the pressure and buffet characteristics for $M_{\infty}=0.85$ and $q_{\infty} \approx 300 \mathrm{lb} / \mathrm{ft}^{2}$ are presented for $\delta_{L E / T E}=0 / 2$. The upper and lower surface pressure profiles for $\eta=0.76$ are given in lig. $10(a)$ for $\alpha_{T}=5.0^{\circ}, 6.0^{\circ}, 8.0^{\circ}$, and $12.0^{\circ}$. The pressure coefficient on the wing upper surface at $x / c=0.96\left(C_{p_{T E}}\right)$ as a function of $\alpha_{T}$ is also shown. In Fig. $10(\mathrm{~b})$, the boundary-layer velocity profiles for $\eta=0.76$ and $x / c=$ 0.96 are shown for $\alpha_{T}$ from $5.2^{\circ}$ to $8.7^{\circ}$. The airplane normal-force coefficient and buffet intensity are given in Fig. 10(c). The pressure profiles show the expected rearward movement of the aft shock location over a supercritical airfoil as $\alpha_{T}$ increases $108.0^{\circ}$. The $C_{p}$ for $\alpha_{T}=8.0^{\circ}$ shows a well-developed supercritical distribution. The pressure profiles indicate that separation at the trailing edge occurs between $\alpha_{T}=8.0^{\circ}$ and $12.0^{\circ}$. Fom the break in the curve for $C_{p_{T} \text { : }}$, separation is seen to occur for $\alpha_{T} \approx 8.6^{\circ}$. The velocity profiles for $\alpha_{T} \leq 8.0^{\circ}$ show larger losses as $\alpha_{T}$ increases from $5.2^{\circ}$ to $8.0^{\circ}$. For $\alpha_{T}=8.6^{\circ}$ and $8.7^{\circ}$, the velocity profiles show incipient separation for the flow at the trailing edge. The buffet data, by the break in the $C_{N_{A}}$ and the BIR point, also show that separation occurs for $\alpha_{T} \approx 8.6^{\circ}$. For $\alpha_{T}<8.6^{\circ}$, the bullet data, as well as the pressure and velocity profiles, indicate that the flow is attached and well-behaved. For $\alpha_{T}>8.6^{\circ}$, the buffet data, as well as the pressure and velocity profiles, indicate the flow is separated.

In Fig. 10(d), information pertinent to the data in Figs. 10(a), (b), and (c) are presented as a function of $\alpha_{T}$. The $C_{p_{T H}}$ and $C_{N_{A}}$ curves are repeated, and $a_{n w T}$ is now shown as a function of $\alpha_{T}$. The curves for aft shock position in percent of $x / c$ and the ratio of local velocity to edge velocity $\left(U / U_{e}\right)$ values for $Y=2 \mathrm{in}$. are also shown. All of the pressure data are for $\eta=0.76$. The shaded band at approximately $\alpha=8.5^{\circ}$ indicates the region of incipient separation. Good agreement was found between all the data sources (trailing-edge pressure, aft shock location, boundary-layer velocity ratio, normal-force coefficient, and the rms of the buffet).

In Fig. 11, the pressure and buffet characteristics for $M_{\infty}=0.85$ and $q_{\infty} \approx 300 \mathrm{lb} / \mathrm{ft}^{2}$ are presented for $\delta_{L E / T \%}=5 / 10$. The upper and lower surface pressure profiles (Fig. 11(a)) are again for $\alpha_{T}=5.0^{\circ}, 6.0^{\circ}, 8.0^{\circ}$, and $10.0^{\circ}$. Boundary-layer data were not obtained for $M_{\infty}=0.85$. However, the boundary-layer data obtained for $M_{\infty}=0.80$ showed separated flow at the trailing edge for all angles of attack studied $\left(\alpha_{T}=4.0^{\circ}\right.$ to 8.0). Because trailing-edge flow separation occurs at lower angles of attack as Mach number increases, the flow at the trailing edge for $M_{\infty}=0.85$ would also be separated. Figure 11 (b) shows $C_{p_{T} \text { : }}$ as a function of $\alpha_{T}$ and Fig. 11(c) shows the buffet characteristics. The pressure profiles show the expected rearward movement of aft shock location as $\alpha_{T}$ increases from $5.0^{\circ}$ to $8.0^{\circ}$. However, unlike the $\delta_{L E / T H}=0 / 2$ profiles, the $\alpha_{T}=$ $5.0^{\circ}$ and $6.0^{\circ}$ profiles have a secondary velocity peak at $x / c \approx 0.75$. For $\alpha_{T}=10.0^{\circ}$, the forward movement of the aft trailing shock indicates that the flow characteristics over the wing have changed, and there is the possibility that the wing has separated flow. None of the pressure profiles have a recovery to $C_{p}=0$ at the trailing edge, which supports the trailing-edge separation indicated by the boundary-layer data. The $C_{p_{T} t}$ curve for $\alpha_{T}=4.0^{\circ}$ to $10.0^{\circ}$ does not have the welldefined break of the $\delta_{L E / T L}=0 / 2$ data, and therefore cannot be easily used to obtain the angle of attack for wing separation. The less negative values occurring at approximately $\alpha_{T}=7.0^{\circ}$ are a result of the secondary shock. From the buffet intensity data in Fig. 11 (c), the BIR occurs for $\alpha_{T} \approx 9.6^{\circ}$, which supports the possible wing separation observed for the $\alpha_{T} \approx 10.0^{\circ}$ pressure profile. The offset in the buffet intersity data and the low level of "buzt" seen in the $a_{n w t}$ time history in Fig. 7(d) support the trailing-edge flow separation observed for the pressure data. It is apparent from these figures that the global (buffet data) and the local data (wing pressure data) do not have the clear-cut interrelationship observed for the $\delta_{L E / T E}=0 / 2$ data. 
Figure 11(d) presents information similar to that shown in Fig. 10(d), except that the pressure-derived section normal-force coefficient $\left(c_{n}\right)$ for $\eta=0.76$ is shown instead of the boundary-layer velocity ratios. All of the pressure data are for $\eta=0.76$. All of the curves derived from the pressure data (trailing-edge pressure, aft shock location, and section $c_{n}$ ) indicate changes in the flow at approximately $\alpha_{T}=7.0^{\circ}$. None of these curves have a definite break that would indicate an extensive region of wing flow separation. The section $c_{n}$ curve indicates that the wing is still performing well as $\alpha_{T}$ increases from $7.0^{\circ}$ to $10.0^{\circ}$, and that an extensive region of wing flow separation may occur for $\alpha_{T}>10.0^{\circ}$. This agrees with the buffet data. The shaded band at approximately $\alpha=10.0^{\circ}$ indicates the region where extensive separation begins.

For the well-behaved flow of the $\delta_{L E / T E}=0 / 2 \mathrm{cam}-$ ber, which is a typical cruise camber shape, the local and global data are in excellent agrecment with respect to the flow properties of the wing. This excellent agreement is not observed for the $\delta_{L E / T E}=5 / 10$ camber, which is a maneuvering camber shape. For the $\delta_{L E / T E}=5 / 10$ camber, the local and global data have similar trends and conclusions but not the clearcut agreement for the breakpoint as observed for the $\delta_{L E / T E}=0 / 2$ camber. A possible reason that the local and global breakpoints are not aligned is because of the presence of a secondary velocity peak observed for $\alpha_{T}=5.0^{\circ}$ and $6.0^{\circ}$ in Fig. 11(a), and for $\alpha_{T}=8.0^{\circ}$ and $10.0^{\circ}$ in Fig. 6

\section{Concluding Remarks}

Selected results from the wing surface and boundarylayer pressures, flight deflection measurement system (FDMS) and buffet studies for the advanced fighter technology integration (AF'TI)/F-111 mission adaptive wing (MAW) Program were presented and discussed with respect to each other. The discussions mainly concerned data for a Mach number of 0.85 , and leadingand trailing-edge camber deflections of $\left(\delta_{L E / T E}\right)=0 / 2$ and $5 / 10$.

From a flight test perspective, providing the technical tools to describe the advantages of a supercritical wing for different cambers is very challenging. This paper describes the different aerodynamic technologies studied on the airplane, and their relationship with each other.

The pressure profiles had the distribution typical of a supercritical airfoil for the $\delta_{L E / T E}=0 / 2$ and $5 / 10$ cambers investigated in this paper. Tho midspan pressure profiles for both cambers illustrated the nearly constant upper surface pressure coeflicient plateaus expected for supercritical wings. The analysis, in terms of pressure profiles with respect to arlegle of attack and shock position, is correlated with the initial separation provided by the buffet analysis and the boundary-layer velocity profiles. The wingtip twist measurements provided an insight into how dynamic pressures for positive normal accelerations affect the wingtip pressure profiles.

For the well-behaved flow of the $\delta_{L E / T E}=0 / 2 \mathrm{cam}-$ ber, which is a typical cruise camber shape, the local and global data are in good agreement with respect to the flow properties of the wing. This good agreement is not observed for the $\delta_{L E / T E}=5 / 10$ camber, which is a maneuvering camber shape. For the $\delta_{L E / T E}=5 / 10$ camber, the local and global data have similar trends and conclusions.

\section{References}

'Sisk, Thomas R., Friend, Edward L., Carr, Peter C., and Sakamoto, Glenn M., Use of Maneuver Flaps to Enhance the Transonic Maneuverability of Fighter Aircroft, NASA TM-X-2844, 1973.

${ }^{2}$ Gould, D.K., Bocing Pre-Design of AFTI-111 Mission Adaptive Wing, Volume II-Aerodynamic Trade Studies, Theoretical Calculations and Wind Tunnel Tests, AFFDI-'Tl-78-73, June 1978.

${ }^{3}$ Nelson, D.W. and Letsinger, Gary R., AFTIF-111 Mission Adaptive Wing Wind Tunnel Analysis Report, Arnold Engineering Development Center PWT-16T, Test No. TF550, Boeing Doc. No. D36510058-1, rev. A, Apr. 1981.

${ }^{4}$ Hall, Joseph M., AFTI/F-111 Flight Control System, AFWAI-TR-87-3012,1987.

${ }^{5}$ Steers, Louis L. and Bussing, Paul R., "Flight Demonstration and Research of the Smooth VariableCamber Wing," Advanced Fighter Technology Integration F-111 Mission Adaptive Wing, NASA CP-3055, 1990, pp. 7197.

${ }^{6}$ Bonnema, Kenneth $L$. and Lokos, William A., "AFTl/1-111 Mission Adaptive Wing Flight Test Instrumentation Overview," Paper No. 89-0084, Instrument Society of America, May 1989.

${ }^{7}$ Advanced Fighter Technology Integration F-111 Mission Adaptive Wing, NASA CP-3055, 1990.

${ }^{8}$ Webb, Lannic D., McCain, William E., and Rose, Lucinda A., Measured and Predicted Pressure Distributions on the AFTI/F-111 Mission Adaptive Wing, NASA TM-100443, 1988. Also published as AIAA-882555, June 1988.

${ }^{9}$ Friend, Edward L. and Thompson, Jeffrey M., "Buffet Characteristics of the Advanced Fighter Technology Integration (AFTI)/ -111 Airplane with the Mission 
Adaptive Wing," Advanced Fighter Technology Integration F-111 Mission Adaptive Wing, NASA CP-3055, 1990, pp. 197-222.

${ }^{10}$ Wong, Kent J., AFTI/F-111 Mission Adaptive Wing Lift and Drag Test Results Volume I, AFFTCTIR-87-02, Apr. 1987.

${ }^{11}$ Phillips Paul W., AFTI/F-111 Mission Adaptive Wing (MAW) Automatic Flight Control System Modes Lift and Drag Characteristics, AFFTC-TR-8903, Feb. 1989.

${ }^{12}$ Painter, Weneth D. and Caw, Lawrence J., Design and Physical Characteristics of the Transonic Aircraft Technology (TACT) Research Aircraft, NASA TM$56048,1979$.

${ }^{13}$ Symposium on Transonic Aircraft Technology (TACT), AFFDL-TR-78-100, Aug. 1978.

${ }^{4}$ Supercritical Wing Technology: A Progress Report on Flight Evaluations, NASA SP-301, 1972.

${ }^{15}$ Ayers, Theordore G. and Hallissy, James B., IIistorical Background and Design Evolution of the Transonic Aircraft Technology Supercritical Wing, NASA TM-81365, 1981.

${ }^{16}$ Baldwin, $\Lambda$. Wayne, Kinsey, Don W., and Lash, Stanley F., Transonic Aircrafi Technology Summary, AFFDL-TM-78-7-FXS, Jan. 1978.

${ }^{17}$ Fehl, John E., AFTI/F-111 Mission Adaptive Wing 1/12 Scale Wind Tunnel Model Inspection, AFWAL-TM-80-114-FIMS, Dec. 1980.

${ }^{18}$ Gould, Douglas K., "AFTl/F-111 Mission Adaptive Wing," Advanced Fighter Technology Integration F-111 Mission Adaptive Wing, NASA CP-3055, 1990 , pp. 29-69.

${ }^{19}$ Webb, Lannie D., Powers, Sheryll Goecke, and Rose, Lucinda A., "Selected Local Flow-Field Measurements on the Advanced Fighter Technology Integration (AFII)/F-111 Aircraft Mission Adaptive Wing," Advanced Fighter Technology Integration F-111 Mission Adaptive Wing, NASA CP-3055, 1990, pp. 115-156.

${ }^{20}$ McCain, William E., "Comparison of Two Prediction Methods with Flight-Measured Wing Surface Pressure Distributions from the Mission Adap tive Wing," Advanced Fighter Technology Integration
F-111 Mission Adaptive Wing, NASA CP-3055, 1990, pp. $157-195$.

${ }^{21}$ Bussing, P.R., AFTI F-111 Final Instrumentation Report, Boeing Doc. No. D365-10016-2, Dec. 1984.

${ }^{22}$ Dudzinski, Thomas $\mathbf{J}$. and Krause, Iloyd N., FlowDirection Measurencnl with Fixed-Position Probes, NASA TM-X-1904, 1969.

${ }^{23}$ DeAngelis, V.M., "In-Fight Deflection Measurement of the HiMAT Aeroelastically Tailored Wing," AIAA-81-2450, Nov. 1981.

${ }^{24}$ Lokos, William A., Predicted and Measured InFlight Wing Deflections of a Forward-Swept-Wing Aircraft, NASA TM-4245, 1990.

${ }^{25}$ DeAngelis, V. Michael and Fodale, Robert, "Electro-Optical Flight Deflection Measurement System," SFTE 18th Annual Symposium Proceedings, SFTE; Technical Paper 22, Sept.-Oct. 1987, pp. 22-1-22-14.

${ }^{26}$ Webb, Lannie D. and Washington, Harold P., Flight Calibration of Compensated and Uncompensated Pitot-Static Airspeed Probes and Application of the Probes to Supersonic Cruise Vehicles, NASA TN D-6827, 1972.

${ }^{27}$ Sakamoto, Glenn M., Aerodynamic Characteristics of a Vane Flow Angularity Sensor System $\mathrm{Ca}$ pable of Measuring Flight Path Accelerations For The Mach Number Range From 0.40 to 2.54, NASA TN D-8242, 1976.

${ }^{28}$ Friend, Edward I. and Matheny, Neil W., Preliminary Flight Measurements of the Buffet Characteristics of Protolype Lightweight Fighter Aircraft, NASA TMX-3549, 1977.

${ }^{29}$ Stanewsky, E. and Basler, D., "Experimental Investigation of Buffet Onset and Penetration on a Supercritical Airfoil at Transonic Speeds," Aircraft Dynamic Loads due to Flow Separation, AGARD-CP-483, 1990, pp. 4-1-4-11.

${ }^{30}$ Nelson, D.W., AFTI/F-111 Aerodynamics Final Report, Boeing Doc. No. D365-10110-1, Feb. 1987.

${ }^{31}$ Friend, Edward I. and Sakamoto, Glenn M., Flight Comparison of the Transonic Agility of the F-111A Aitplane and the F-111 Supercritical Wing Airplane, NASA TP-1368, 1978. 


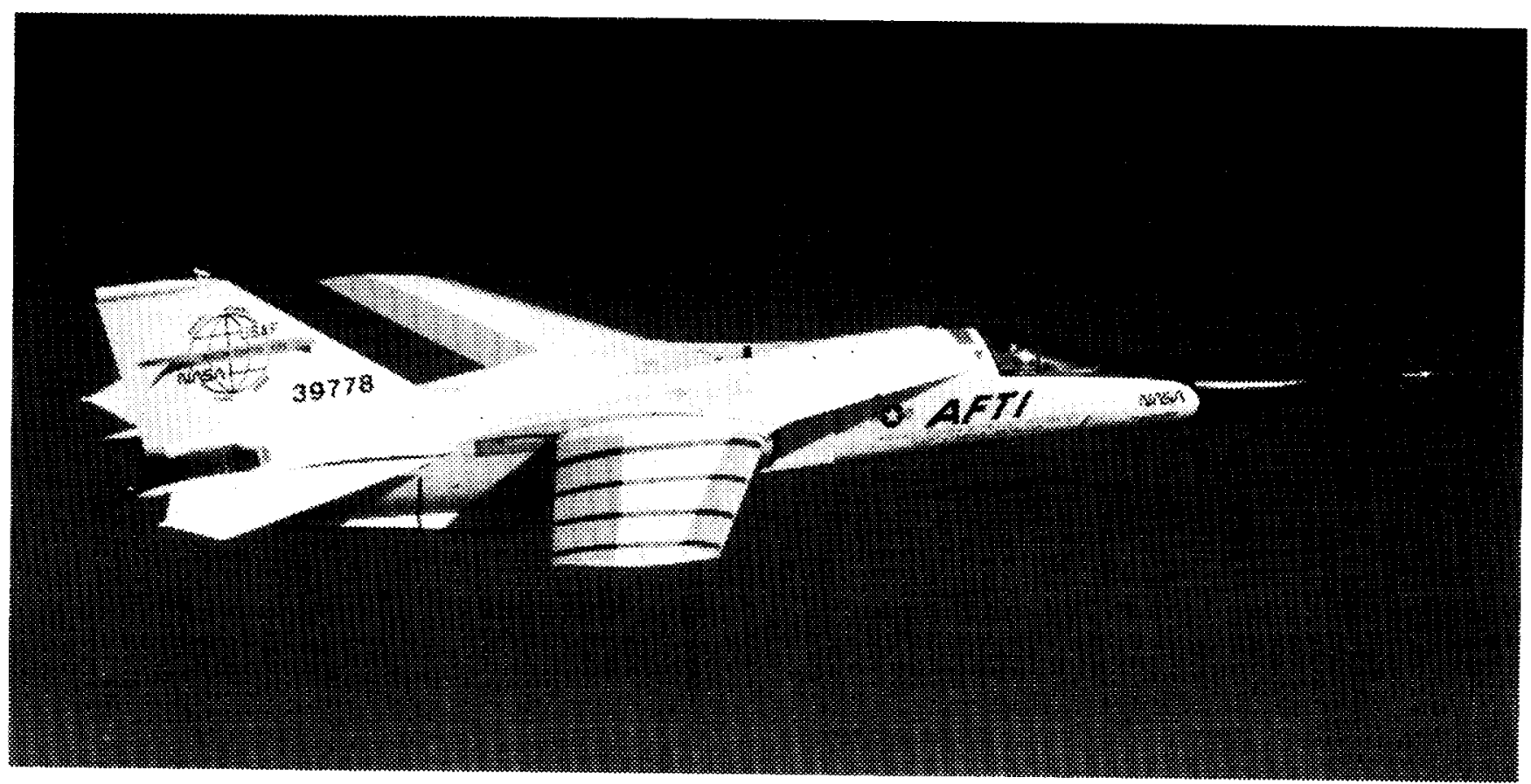

(a) Airplane in flight. Chordwise dark areas on the right wing indicate the four semispan locations of pressure orifices.

Fig. 1 AFTI/F-111 MAW airplane and wing shape. 

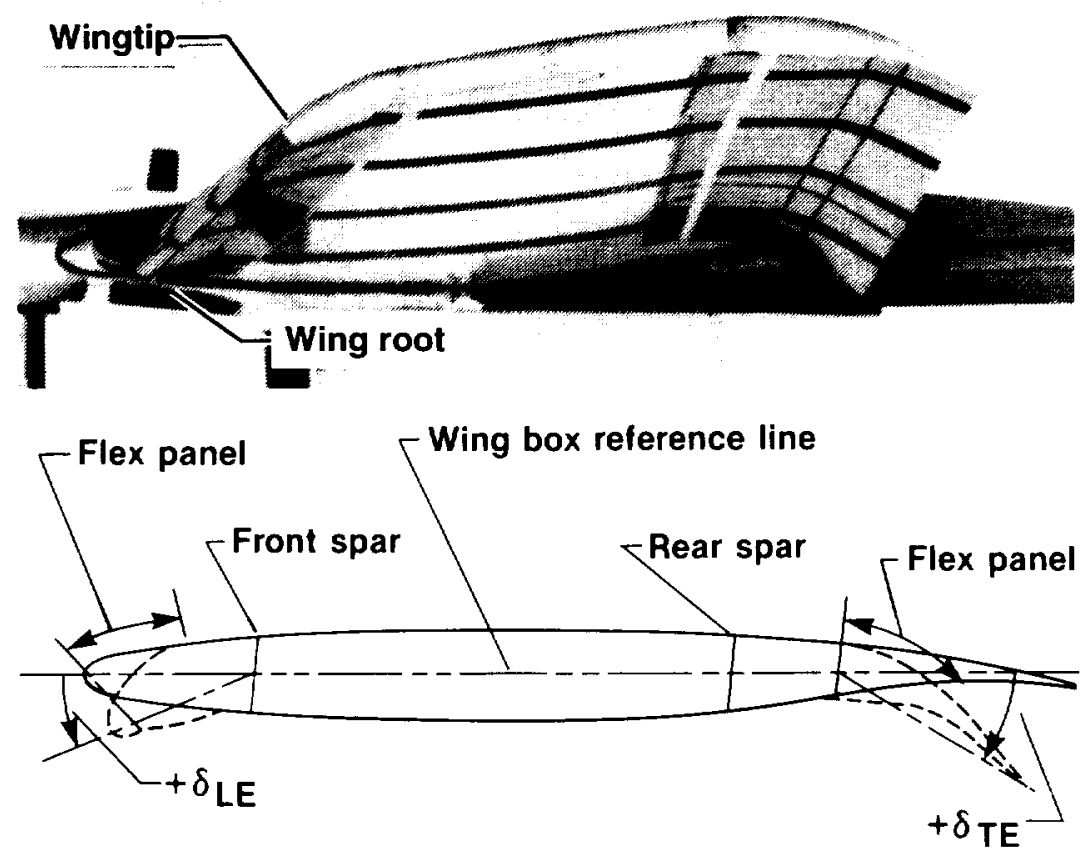

920412

(b) The MAW smooth variable-camber flap shape.

Fig. 1 Concluded. 


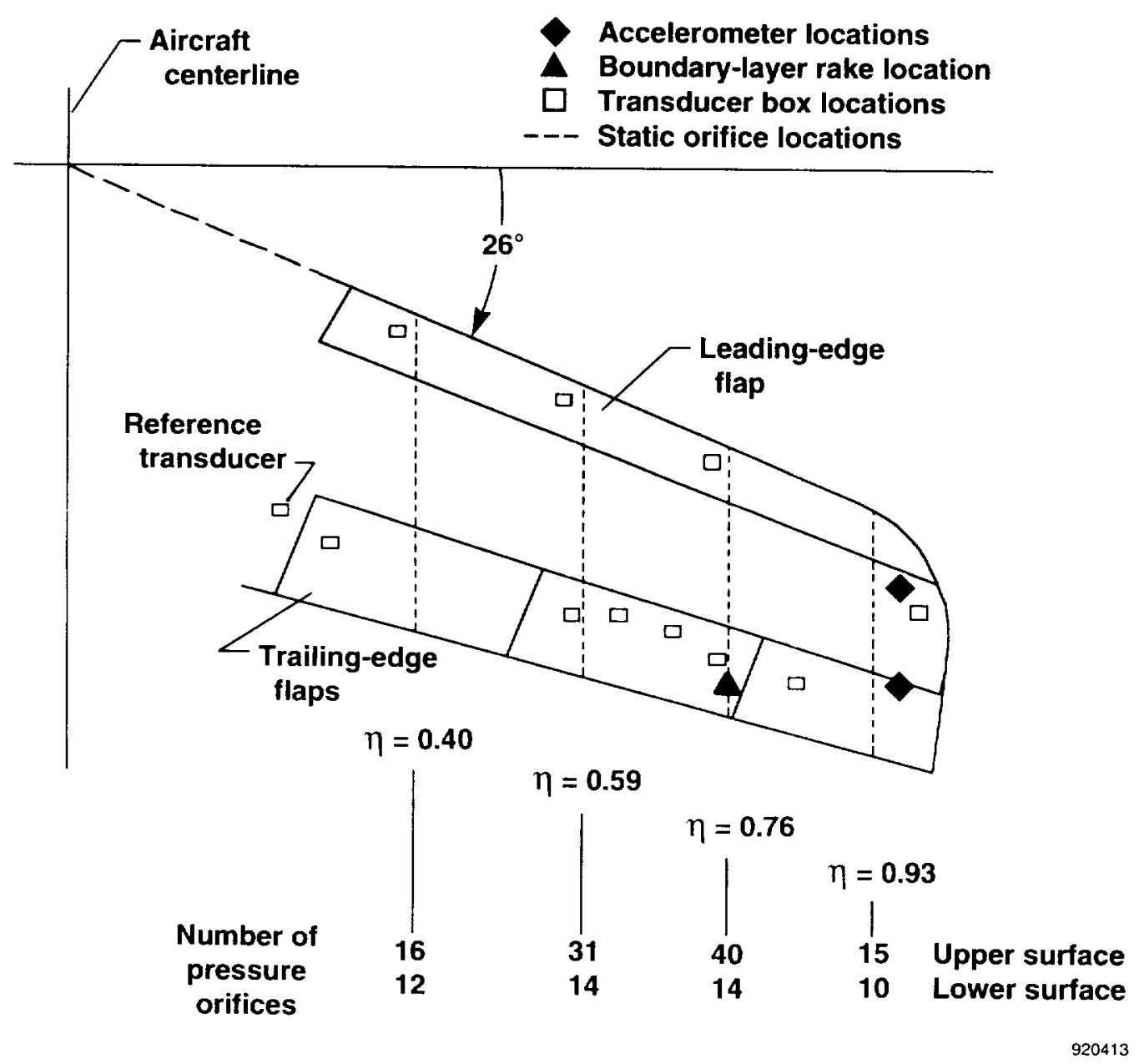

(a) Semispan locations of surface pressure orifices, boundary-layer rake, pressure instrumentation, and wingtip accelerometers for the right wing.

Fig. 2 Experiment locations and description. 


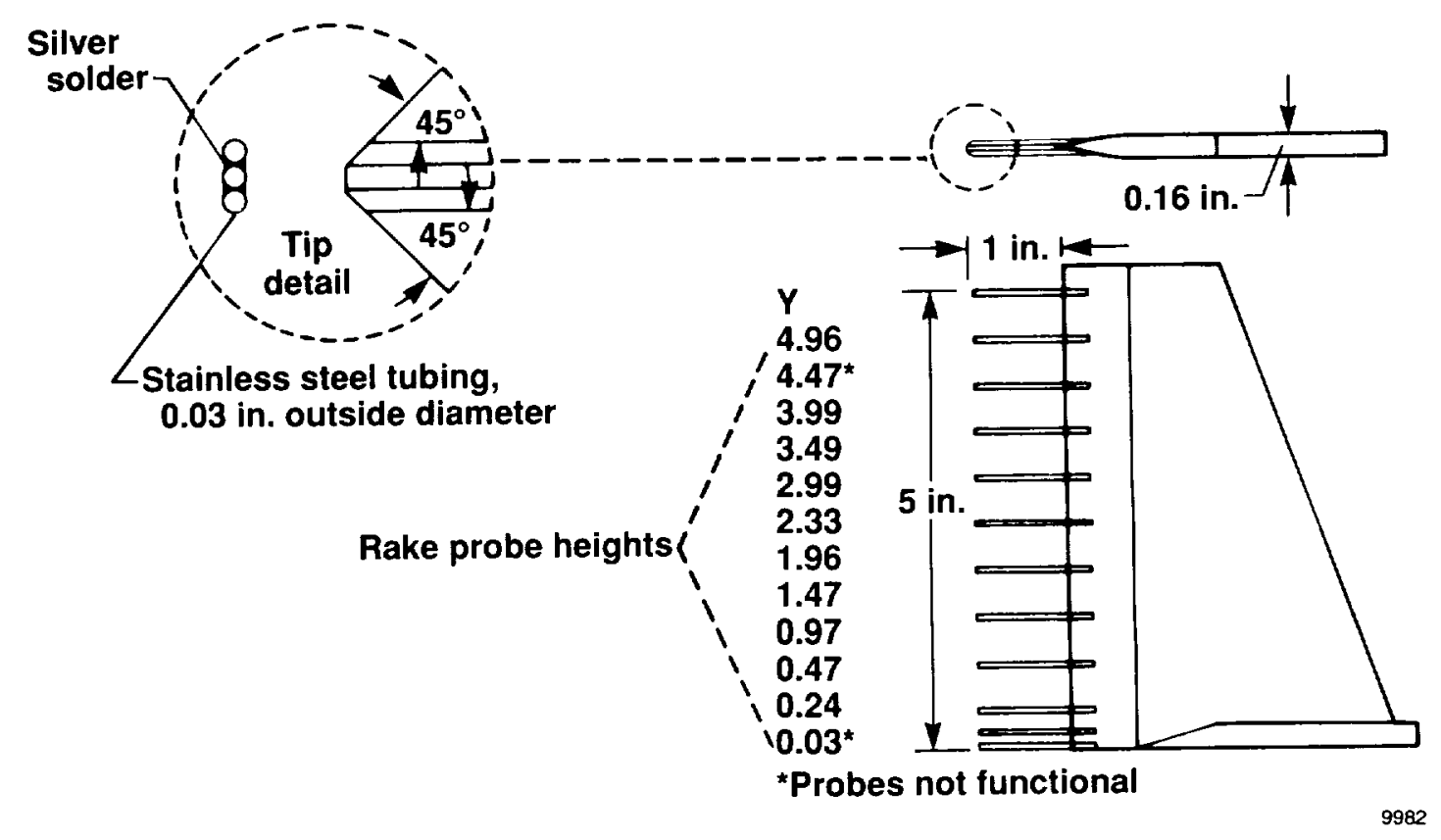

(b) Boundary-layer rake.

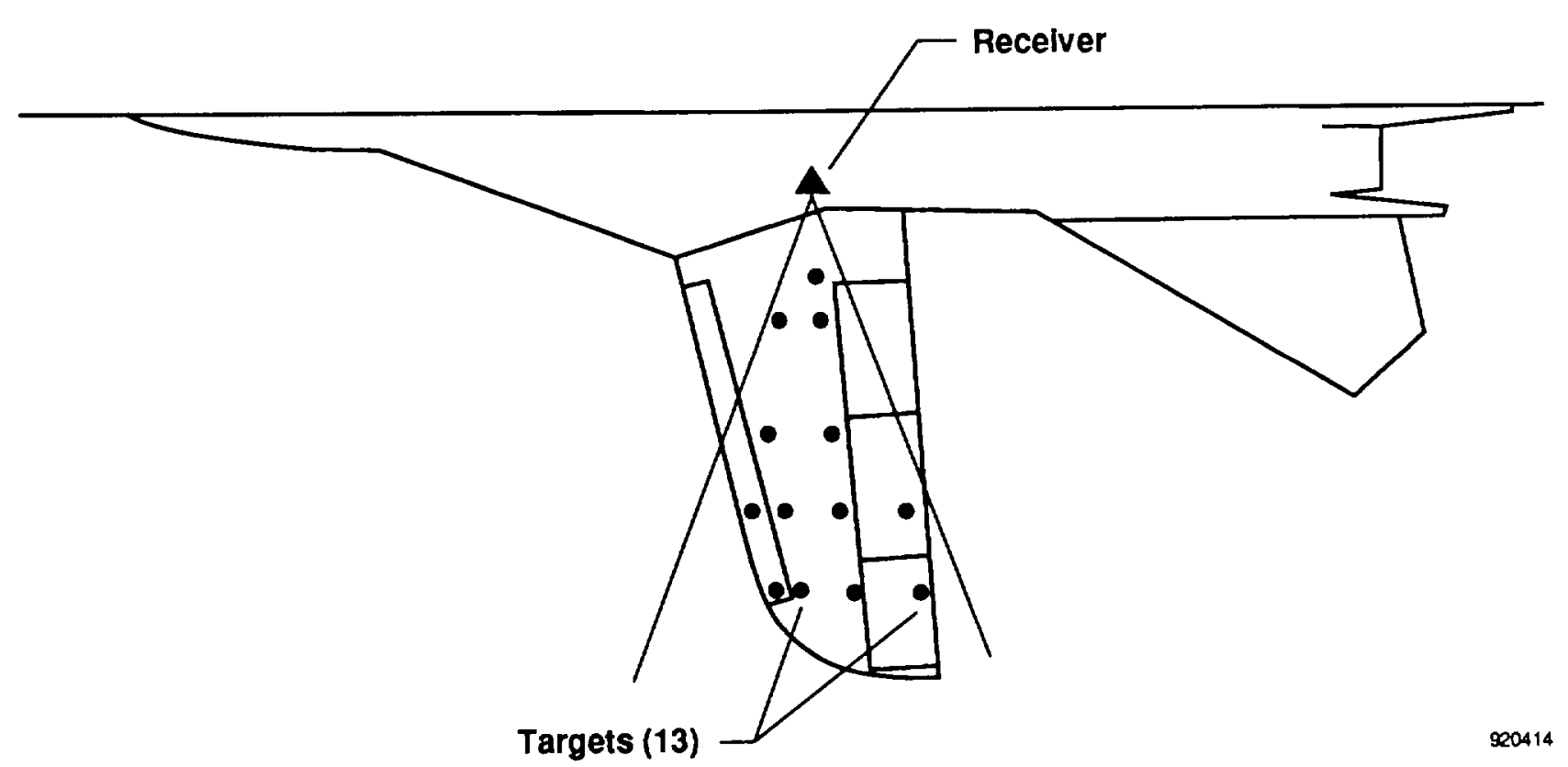

(c) FDMS target locations on the lower surface of the left wing.

Fig. 2 Concluded. 

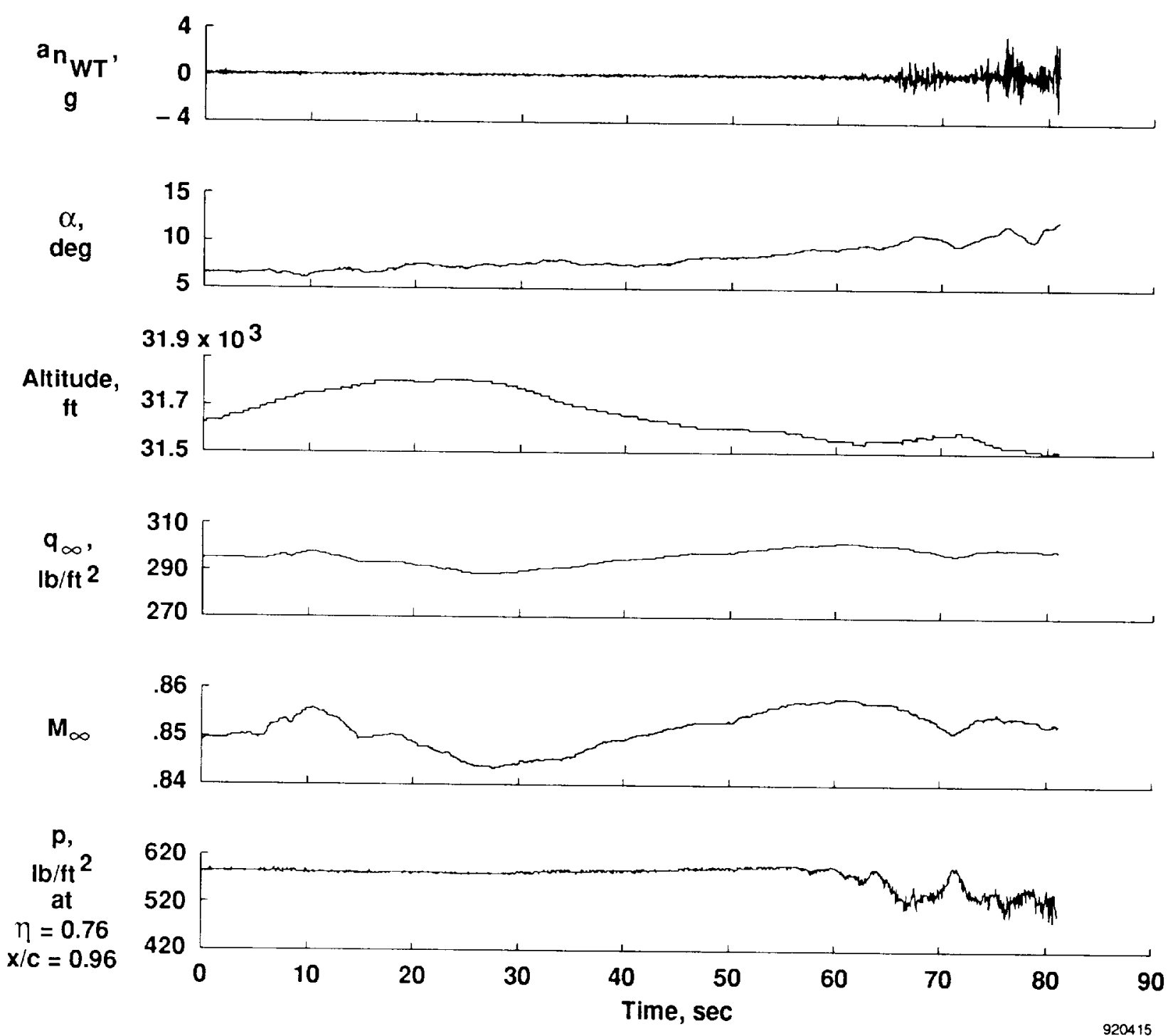

Fig. 3 Time history of typical windup-turn maneuver used to obtain wing pressure FDMS and boundary-layer data; $M_{\infty} \approx 0.85, q_{\infty} \approx 300 \mathrm{lb} / \mathrm{ft}^{2}$, and $\delta_{L E / T E}=0 / 2$. 

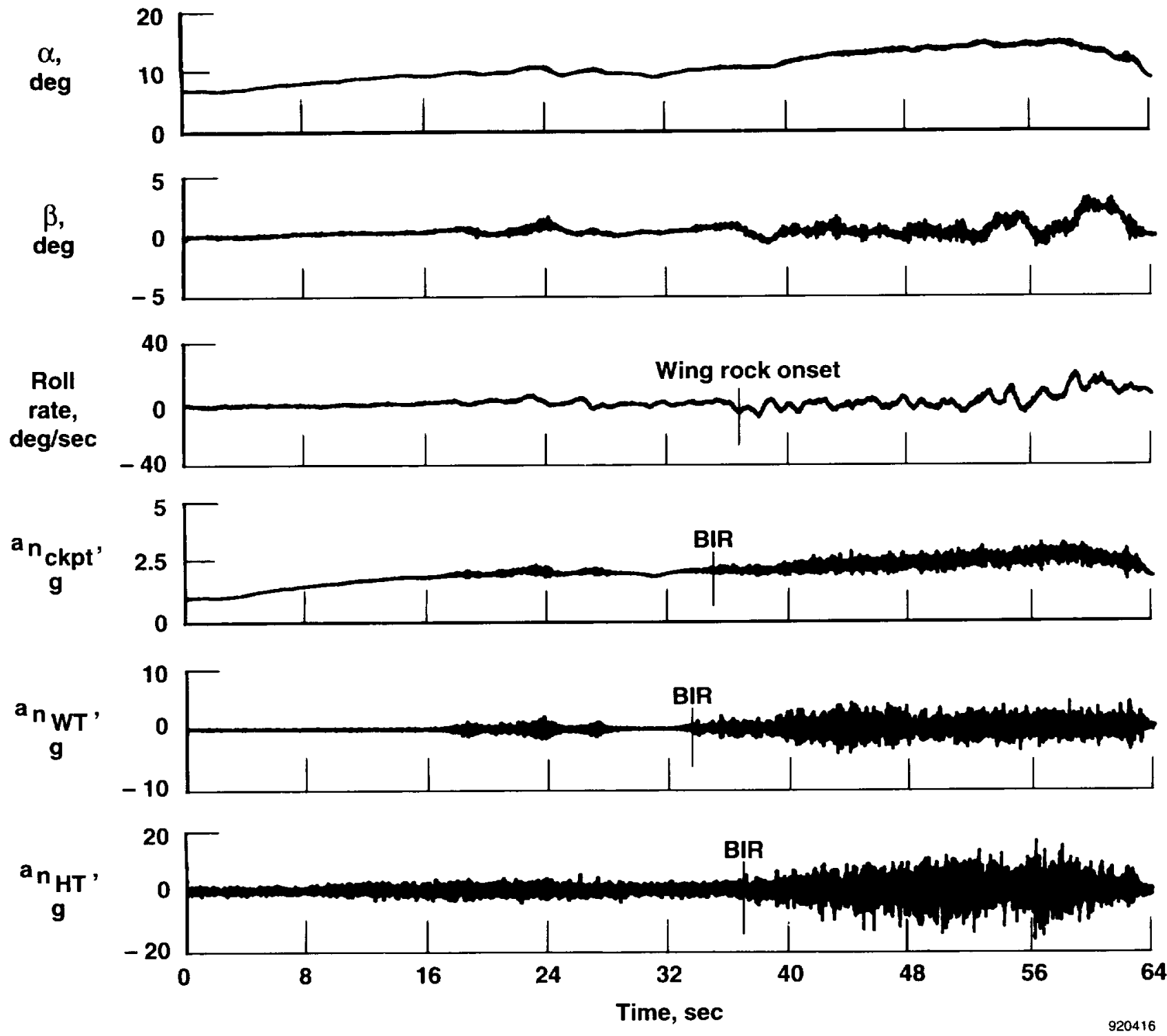

Fig. 4 Time history of typical windup-turn maneuver used to obtain buffet data; $M_{\infty} \approx 0.85, q_{\infty} \approx 300 \mathrm{lb} / \mathrm{ft}^{2}$, and $\delta_{L E / T E}=0 / 2$. 


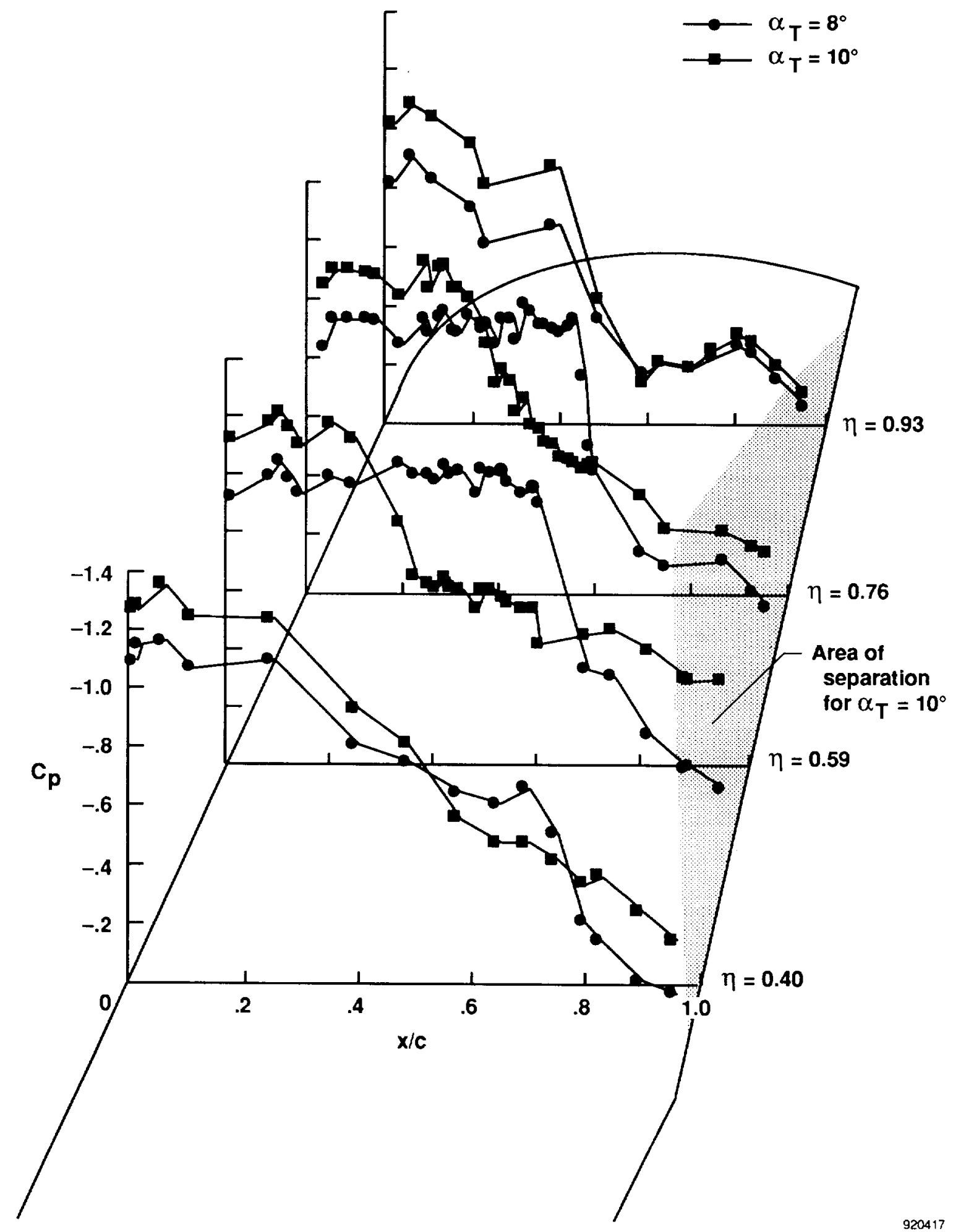

Fig. 5 Steady chordwise pressure distributions at four semispan locations for $M_{\infty}=0.85, q_{\infty} \approx 300 \mathrm{lb} / \mathrm{ft}^{2}$, and $\delta_{L E / T E}=0 / 2$. No separation at $\alpha_{T}=8.0^{\circ}$. 


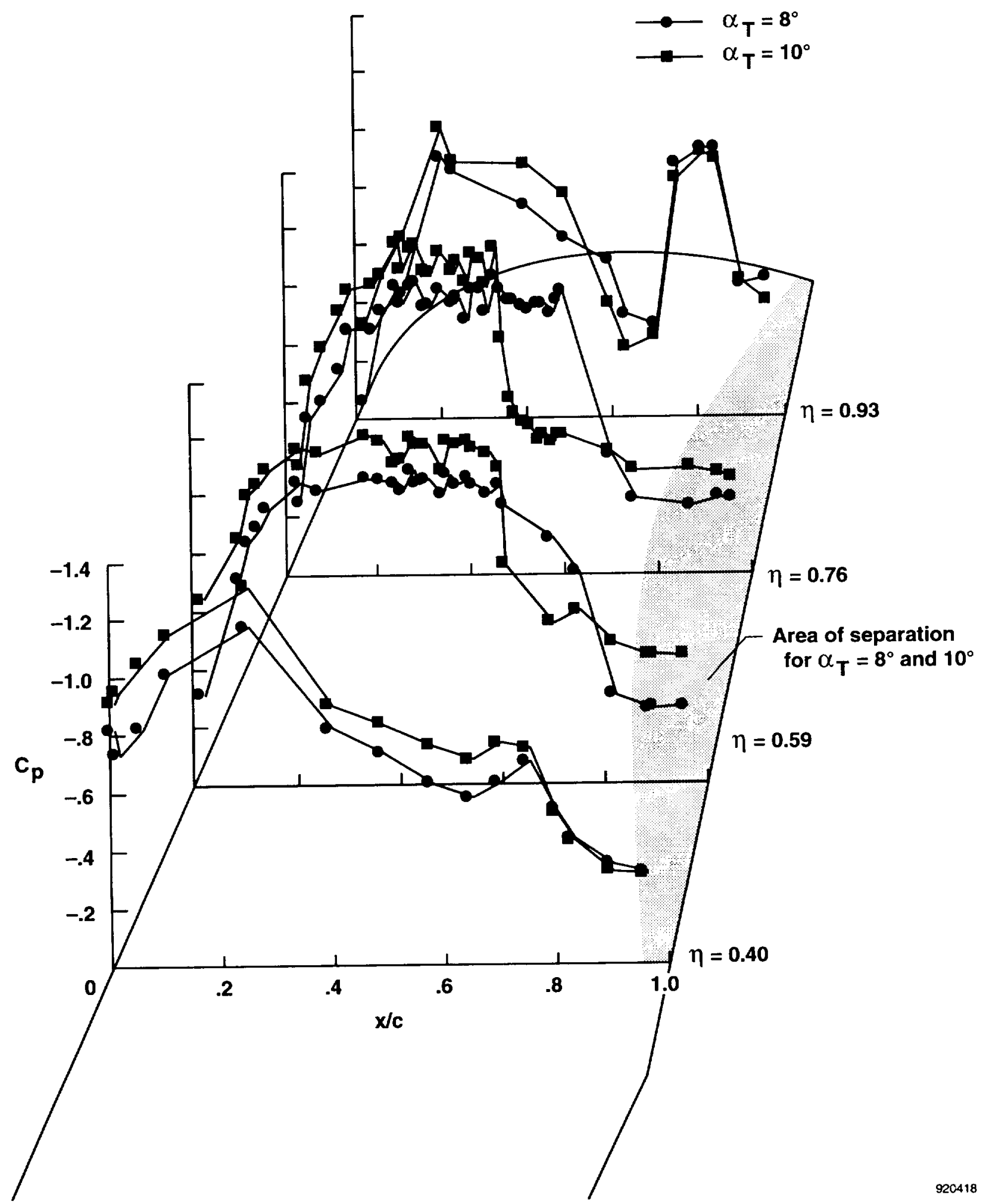

Fig. 6 Steady chordwise pressure distributions at four semispan locations for $M_{\infty}=0.85, q_{\infty} \approx 300 \mathrm{lb} / \mathrm{ft}^{2}$, and $\delta_{L E / T E}=5 / 10$. 


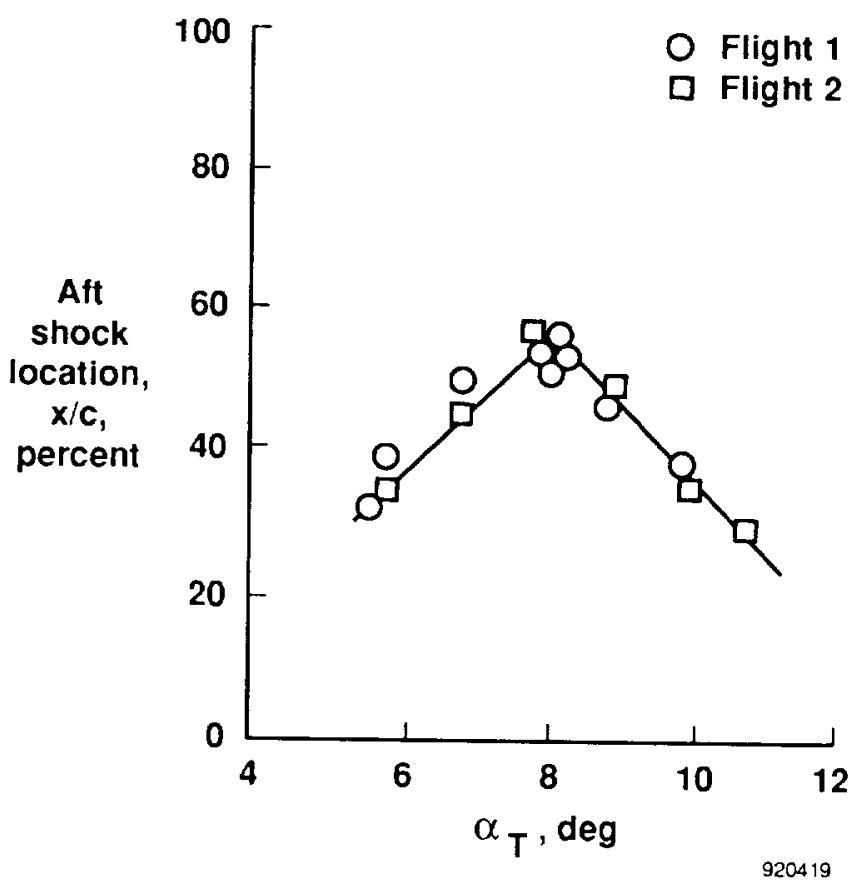

(a) Relationship of aft shock location with angle of attack; $M_{\infty}=0.85, \delta_{L E / T E}=0 / 2$, and $\eta=0.76$.

Fig. 7 Aft shock position as a function of angle of attack and windup-lum time histories of selected chordwise pressures, trailing-edge pressures, and wingtip accelerations, $q_{\infty} \approx 300 \mathrm{lb} / \mathrm{ft}^{2}$. 


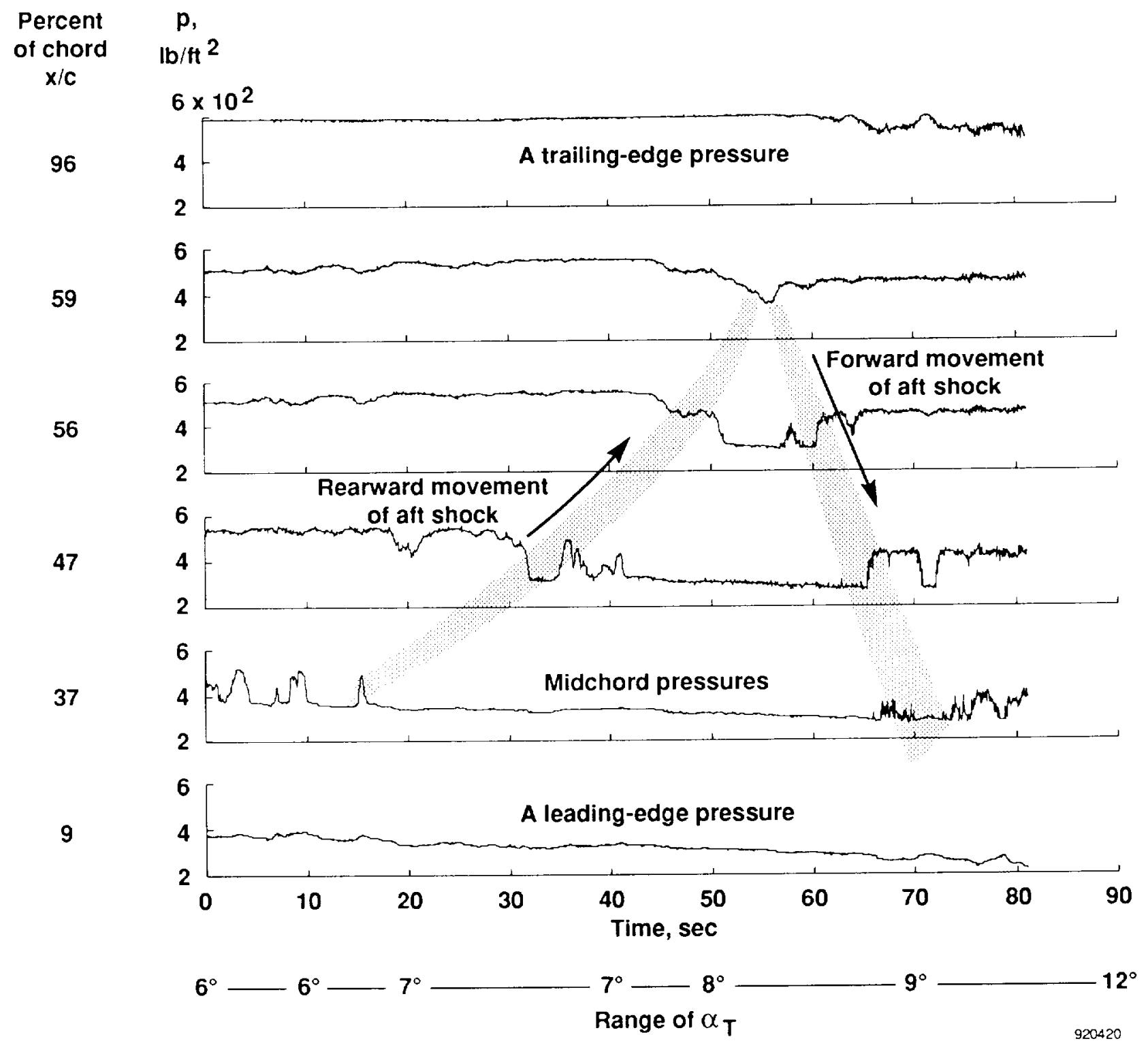

(b) Windup-turn time histury of selected chordwise pressures showing movernent of shock location; $M_{\infty} \approx 0.85$, $\delta_{L, F / T H}=0 / 2$, and $\eta=0.76$.

Fig. 7 Continued. 


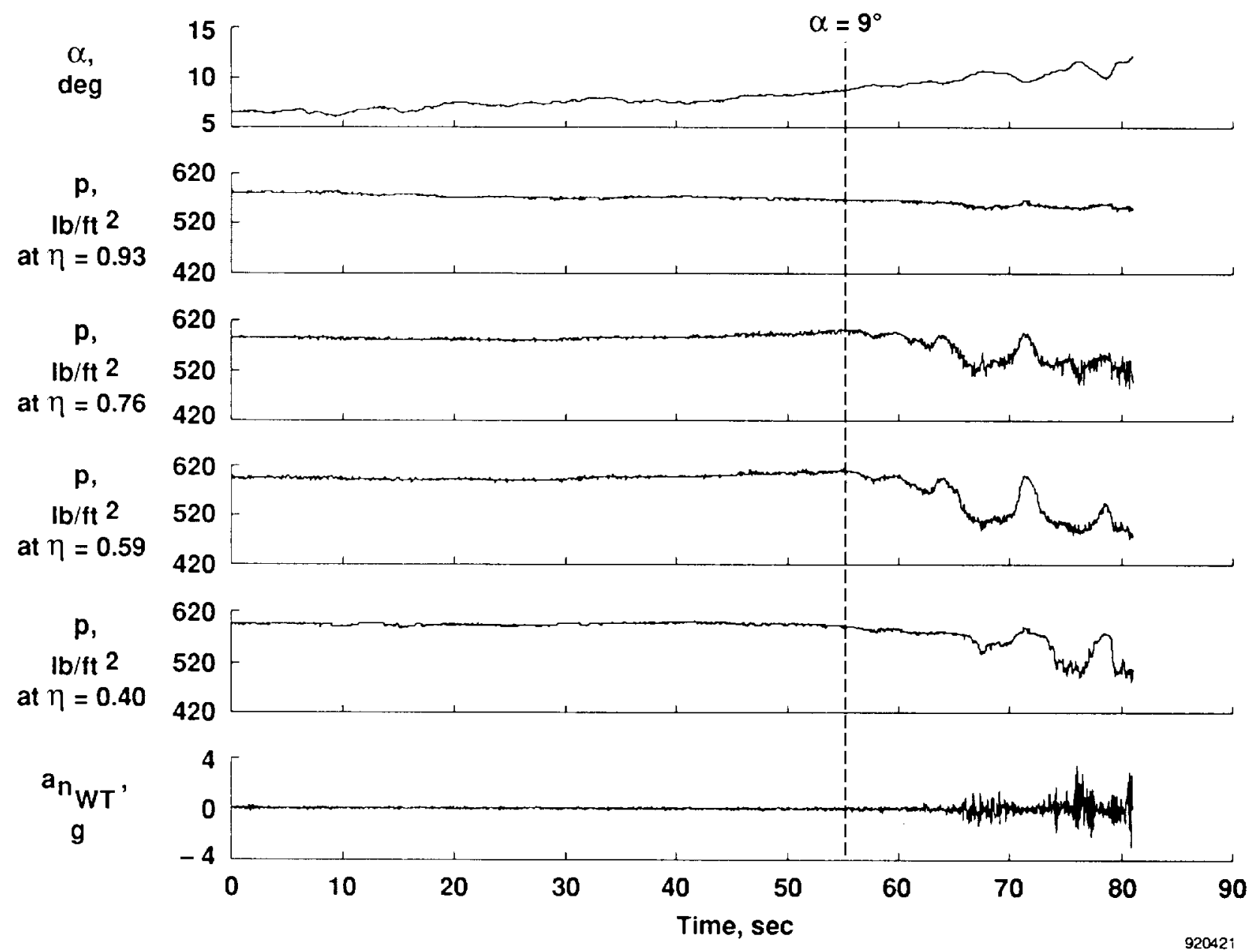

(c) Time history of trailing-edge wing pressures $(x / c=0.96)$ and wingtip accelerometers as angle of attack increases; $M_{\infty} \approx 0.85$ and $\delta_{L E / T V}=0 / 2$.

Fig. 7 Continued. 


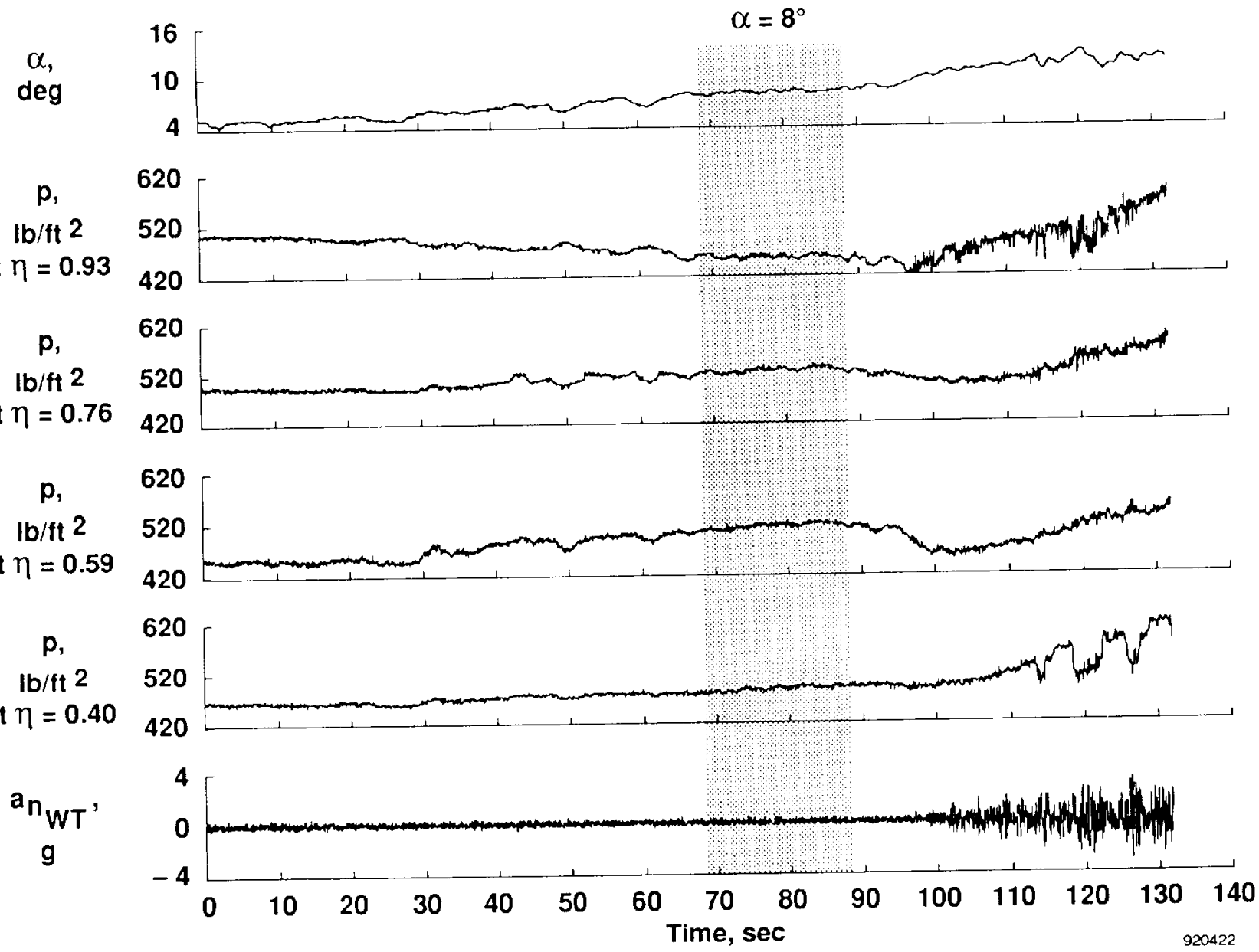

(d) Time history of trailing-edge wing pressures $(x / c=0.96)$ and wingtip accelerometers as angle of attack increases, $M_{\infty} \approx 0.85$ and $\delta_{L E / T H}=5 / 10$.

Fig. 7 Concluded. 


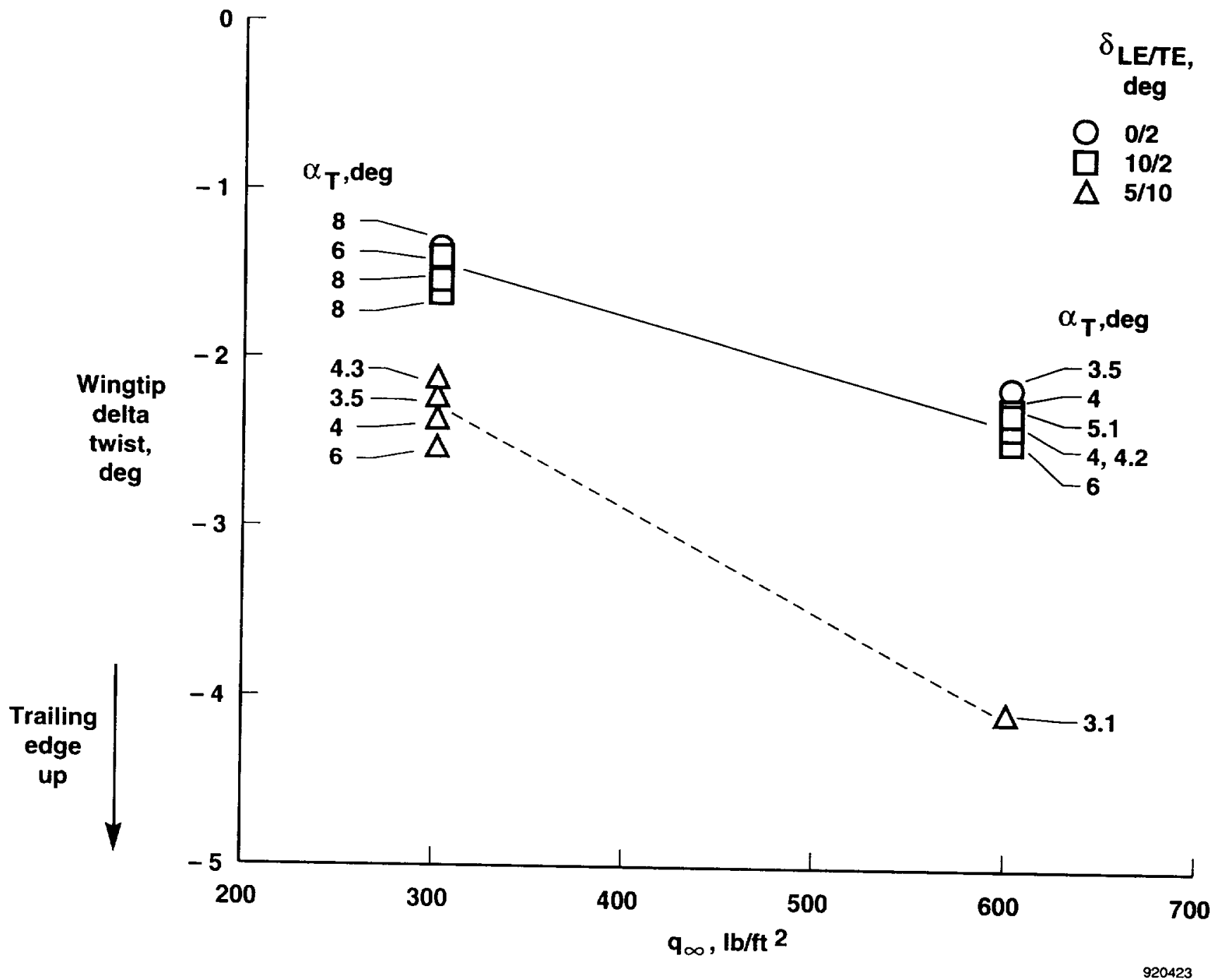

(a) FDMS wingtip delta twist as a function of dynamic pressure for three cambers.

Fig. 8 Comparison of FIMS measured wingtip delta twist with two pressure profiles for $M_{\infty}=0.85$ and $q_{\infty} \approx$
300 and $600 \mathrm{lb} / \mathrm{ft}^{2}$. 


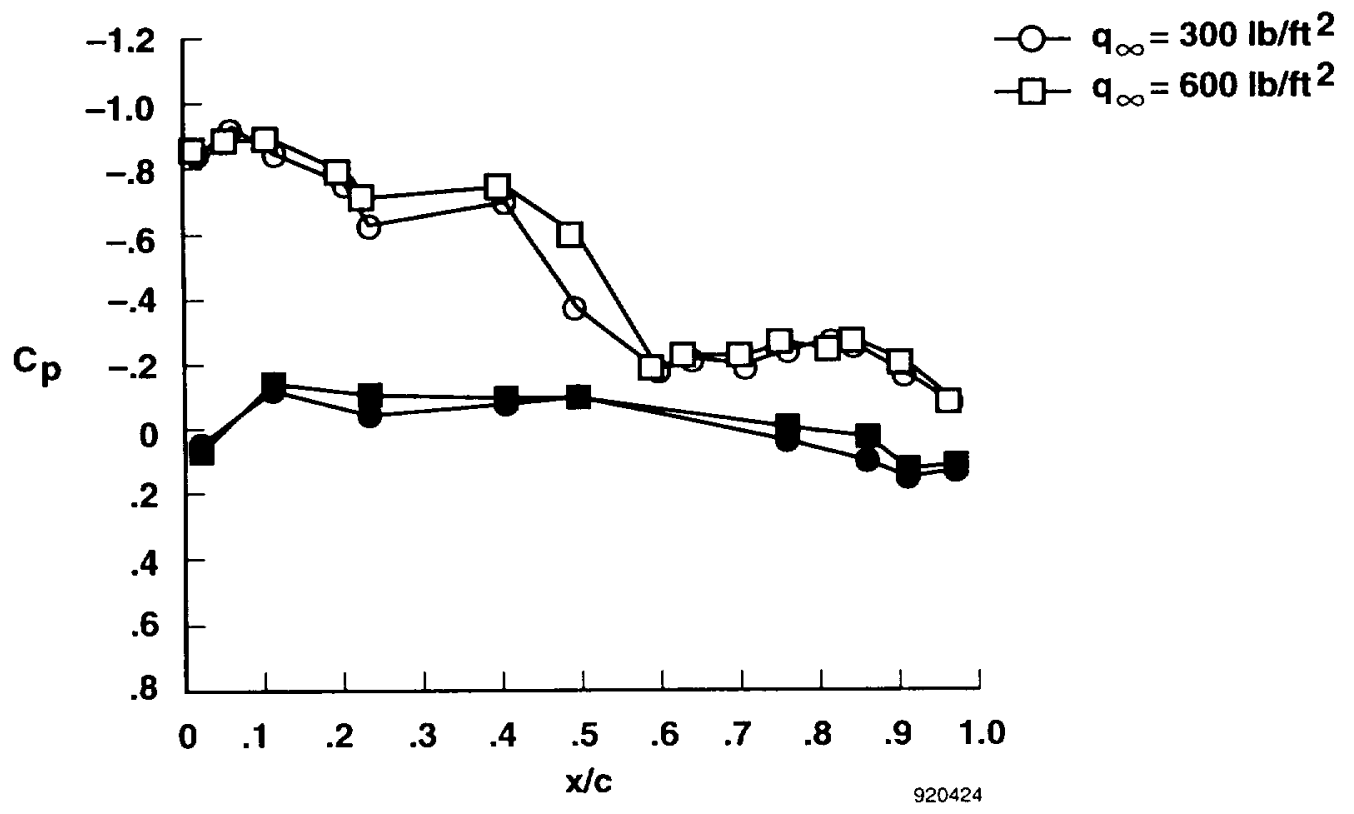

(b) $\delta_{L E / T E}=0 / 2, \eta=0.93, \alpha_{T}=8.0^{\circ}$.

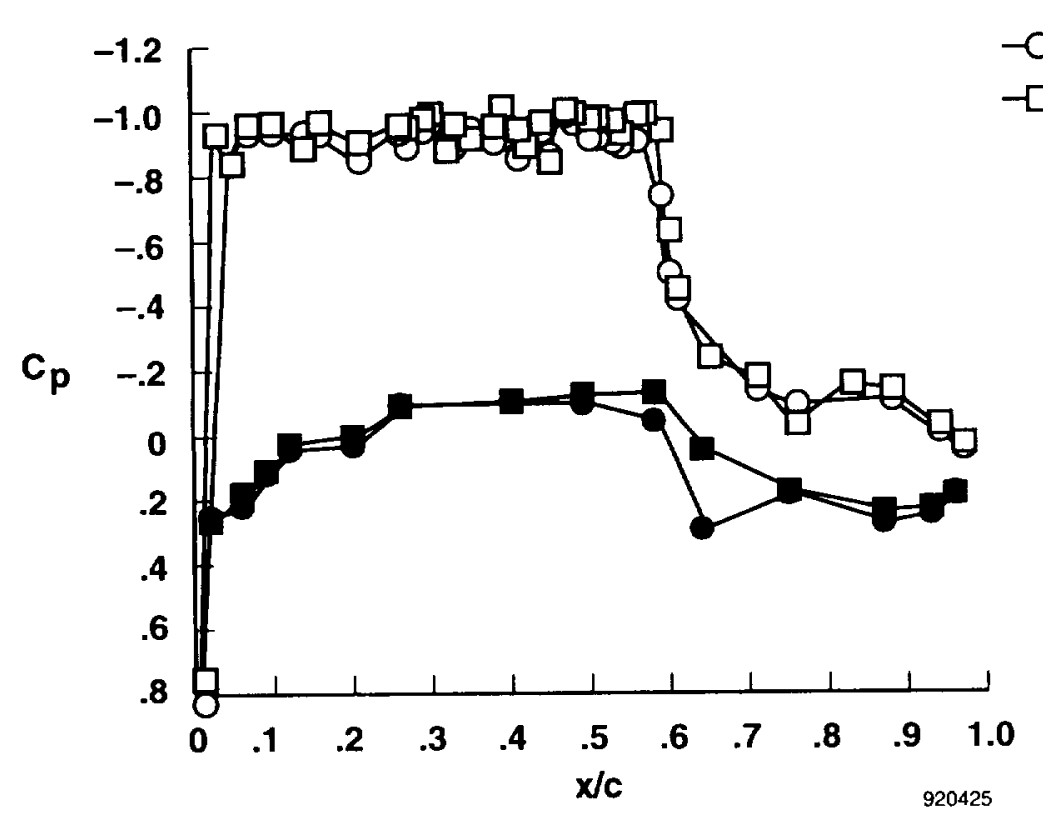

(c) $\delta_{L E / T E}=0 / 2, \eta=0.76, \alpha_{T}=8.0^{\circ}$.

Fig. 8 Concluded. 


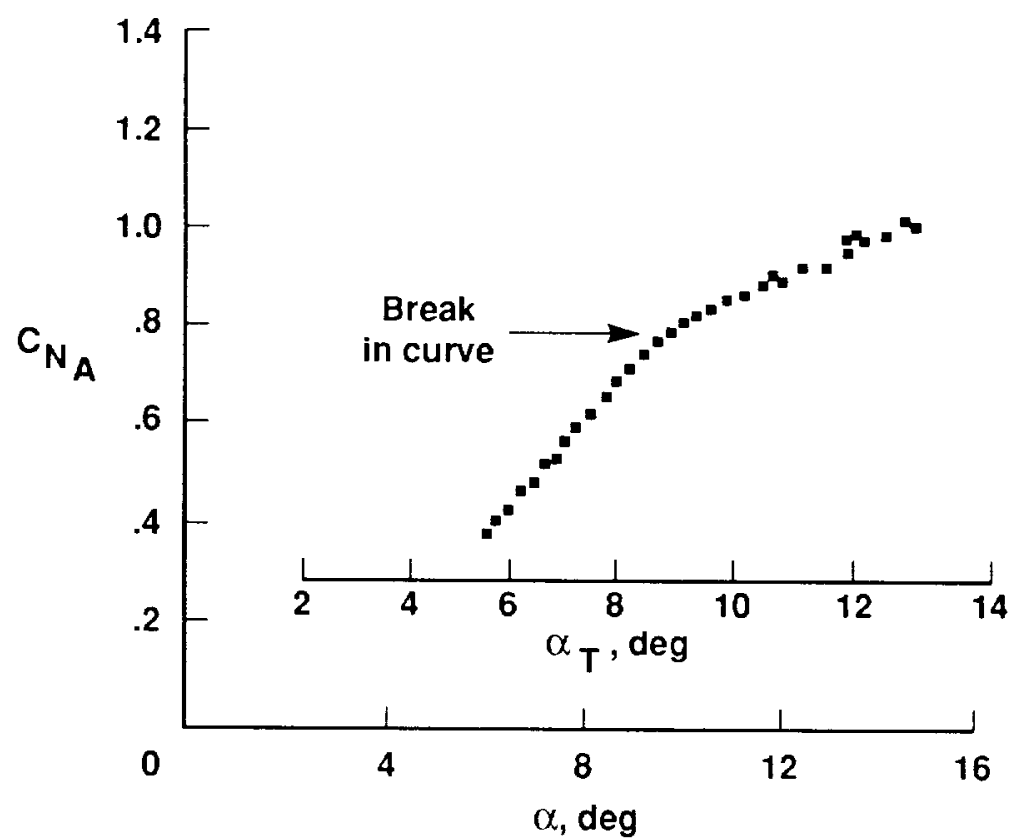

(a) $\delta_{L E / T E}=0 / 2$.

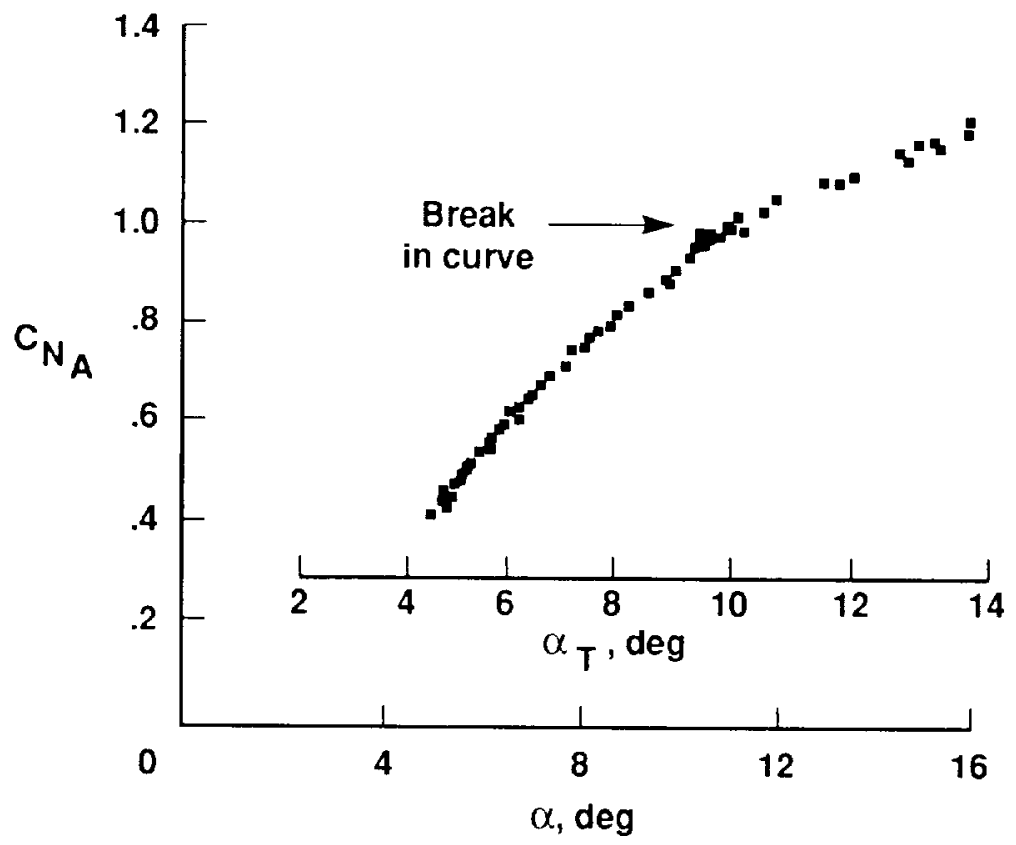

(b) $\delta_{L E / T E}=5 / 10$.
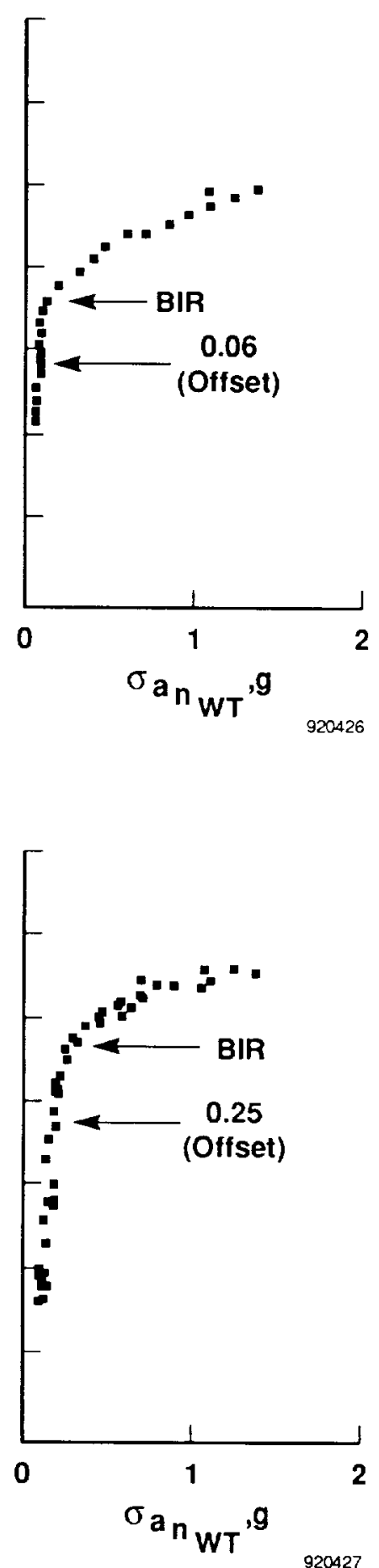

Fig. 9 Variation of airplane and normal-force coefficient with angle of attack and bulfet intensity for $M_{\infty}=0.85$ and $\delta_{L E / T E}=0 / 2$ and $5 / 10$. 


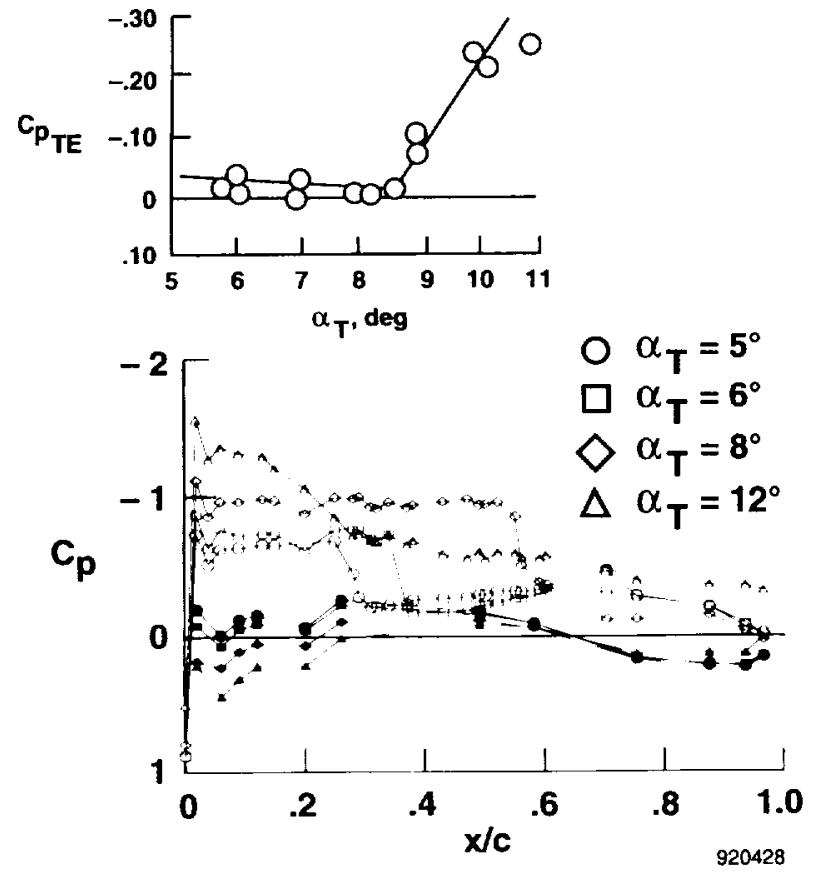

(a) Pressure profiles for several angles of attack, $\eta=$ 0.76 (see inset for trailing-edge pressures). Solid symbols are lower surface $C_{p}$.

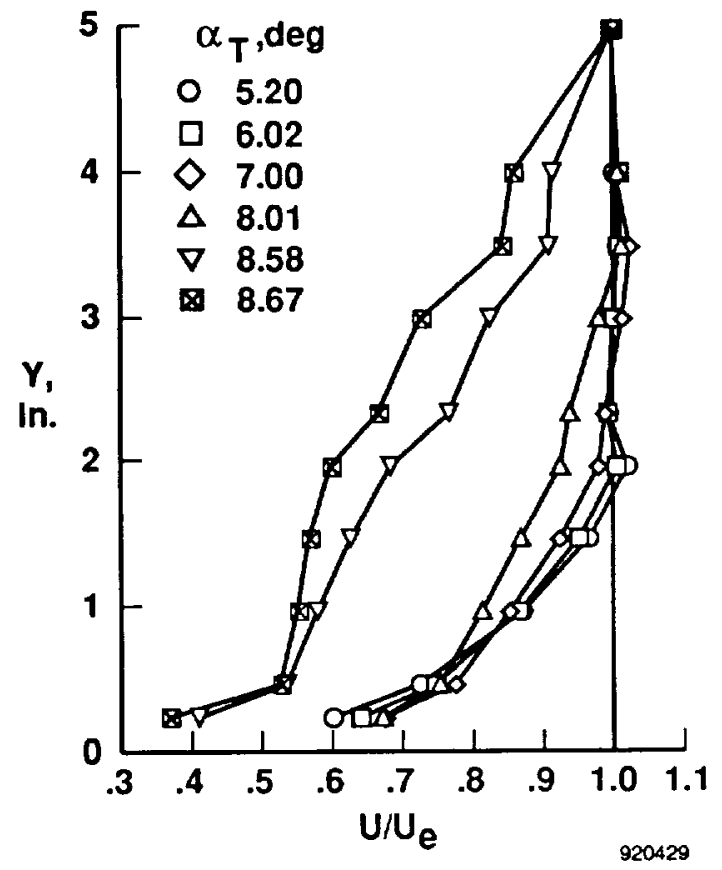

(b) Boundary-layer profiles for several angles of attack at $x / c=0.96$ and $\eta=0.76$.
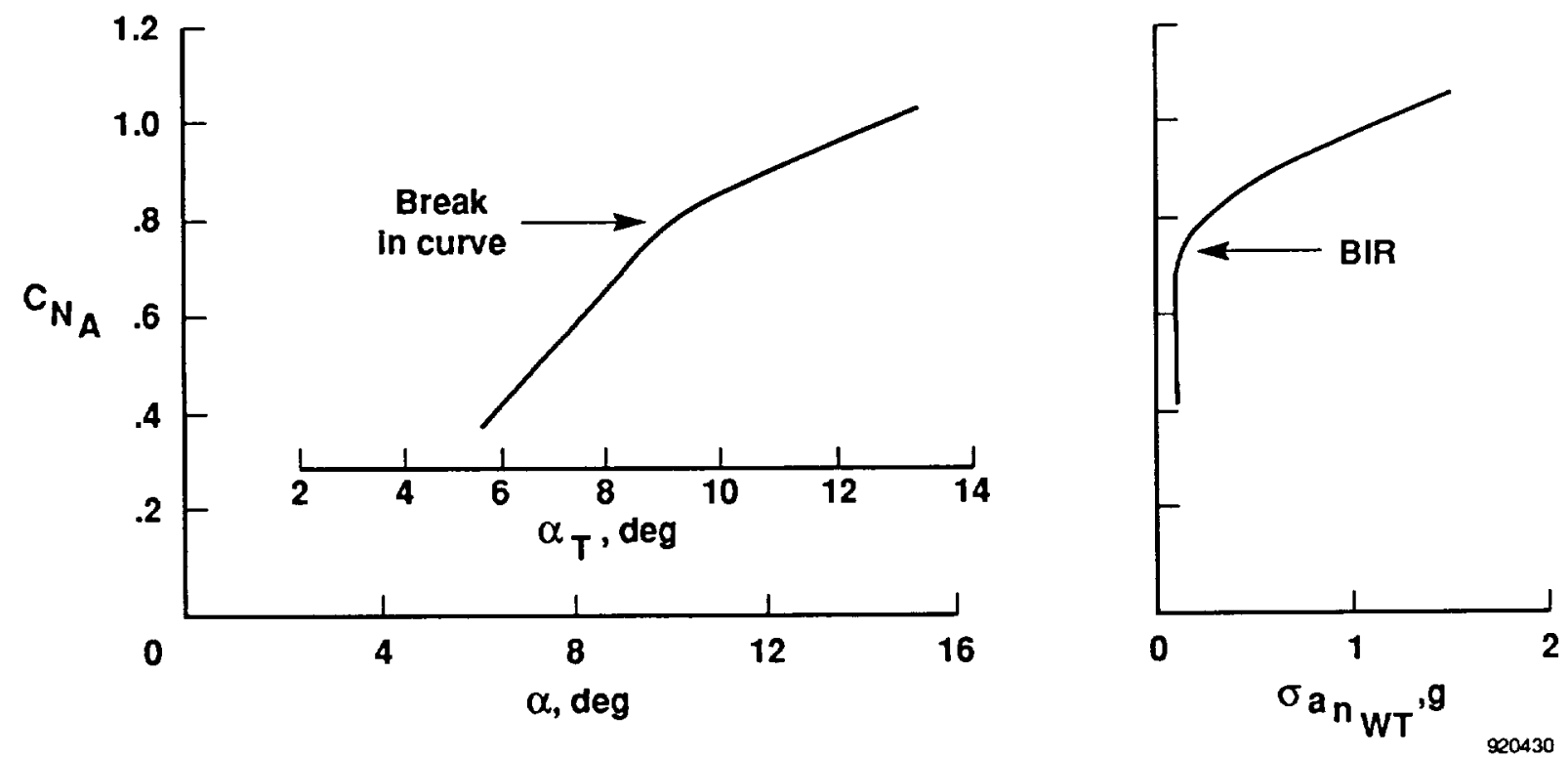

(c) Variation of airplane normal-force coefficient characteristics with angle of attack and buffet intensity.

Fig. 10 The angle-of-attack relationship between pressure coefficients, boundary-layer profiles, and buffet characteristics for $M_{\infty}=0.85, q_{\infty} \approx 300 \mathrm{lb} / \mathrm{ft}^{2}$, and $\delta_{L E / T E}=0 / 2$. 


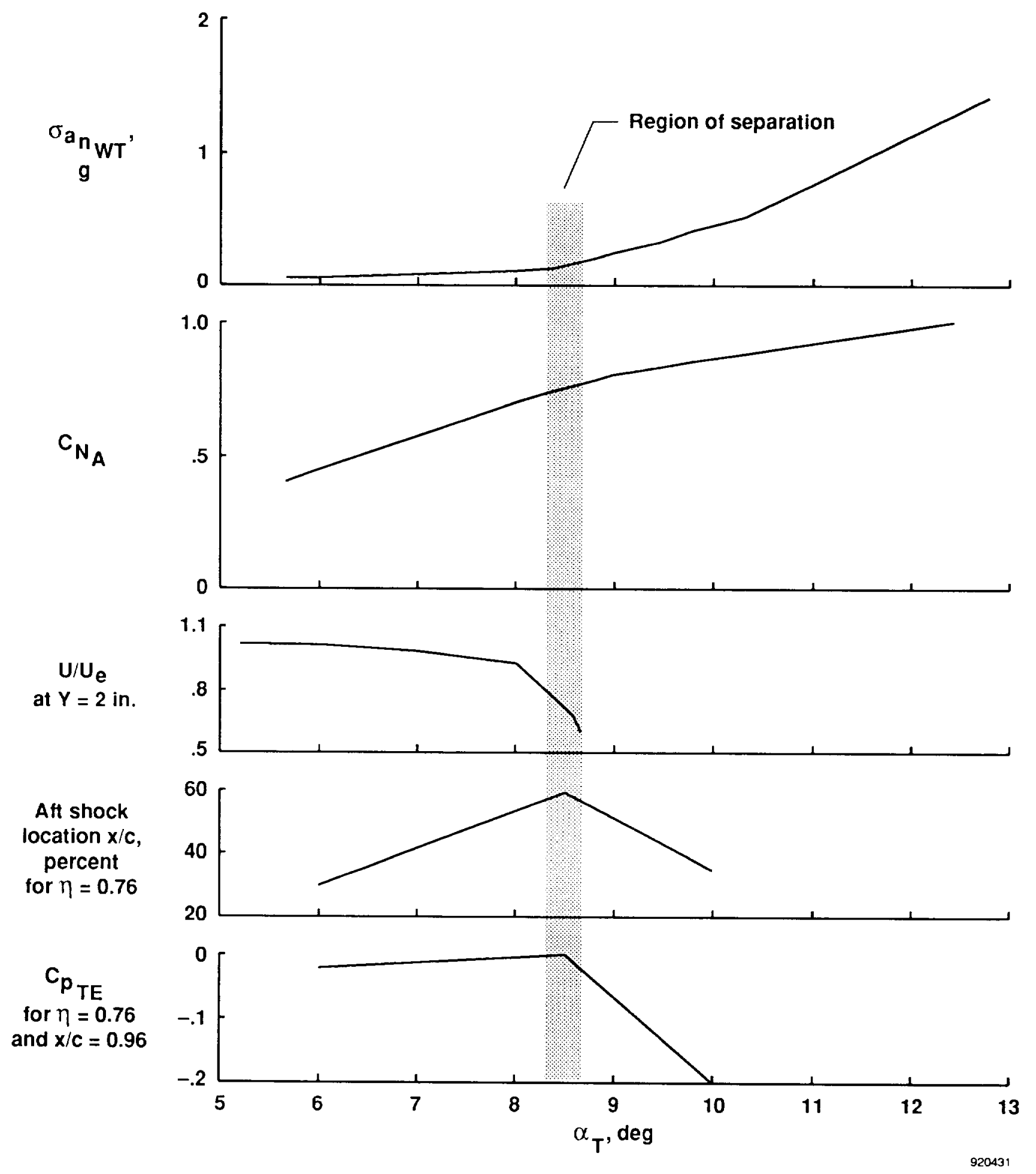

(d) Summary of breakpoints for pressure- and bulfet-derived quantities.

Fig. 10 Concluded. 


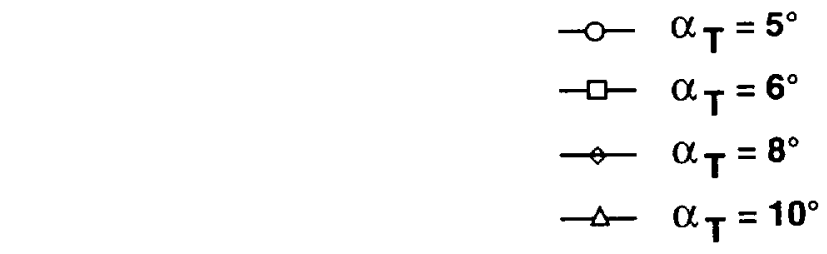

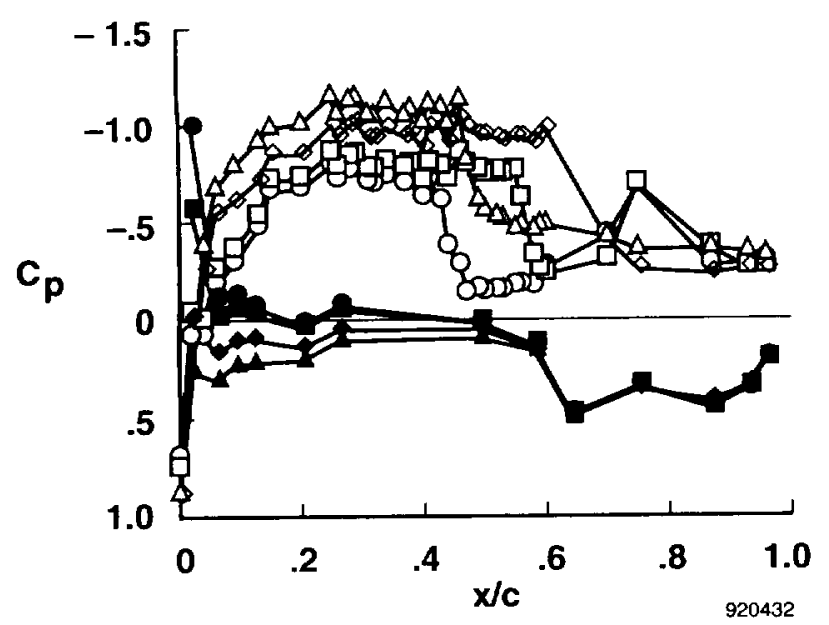

(a) Pressure profiles for several angles of attack, $\eta=$ 0.76 . Solid symbols are lower surface $C_{p}$.

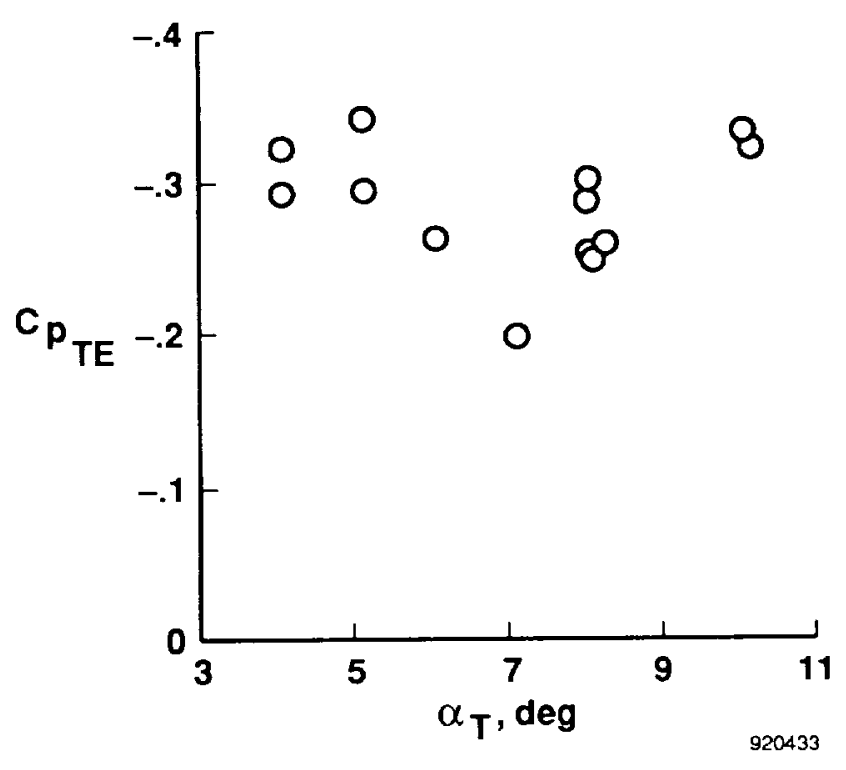

(b) Variation of upper surface pressure coefficients with angle of attack at $x / c=0.96$ and $\eta=0.76$.
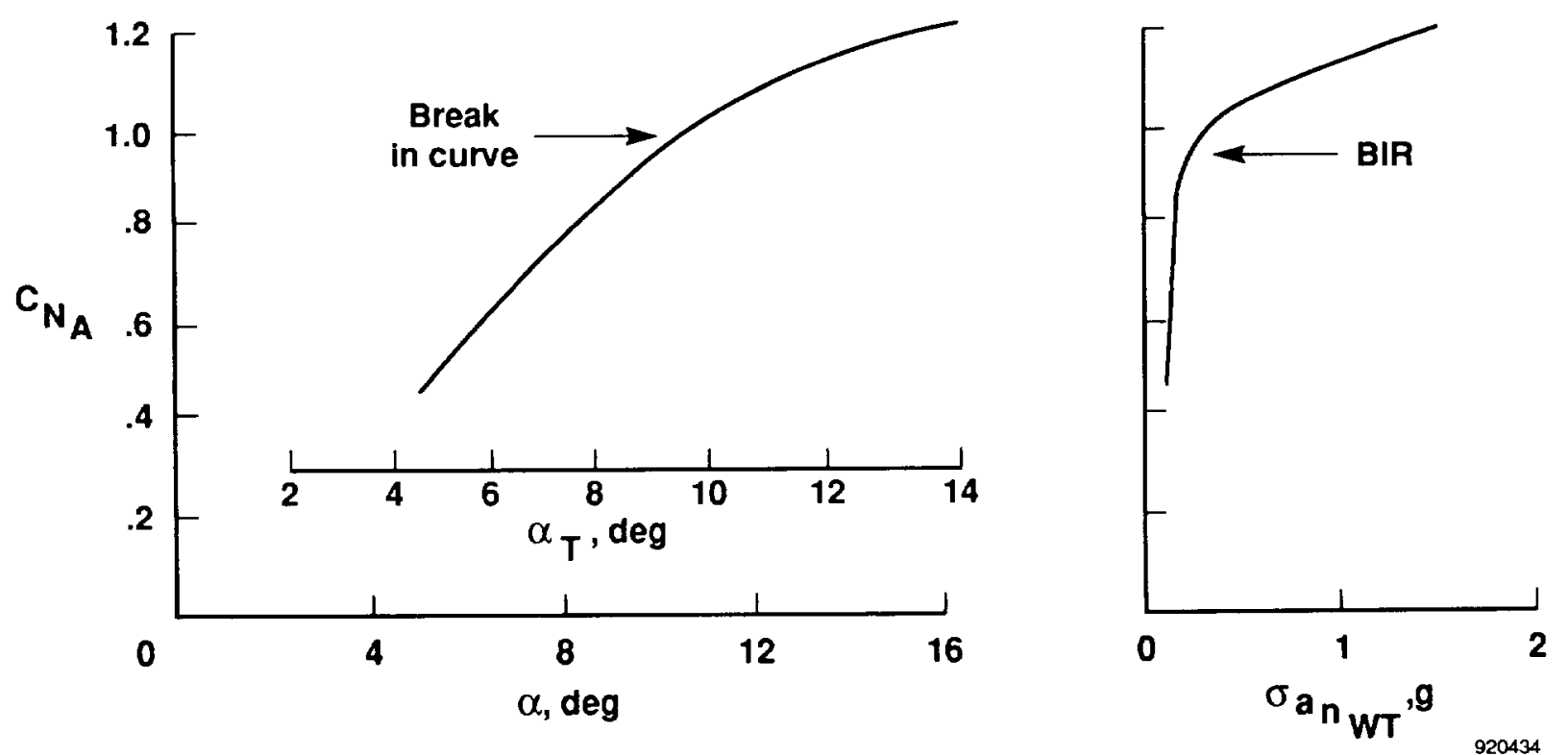

(c) Variation of airplane normal-force coefficient characteristics with angle of attack and buffet intensity.

l'ig. 11 The angle-of-attack relationship between pressure coefficients and buffet characteristics for $M_{\infty}=0.85$, $q_{\infty} \approx 300 \mathrm{lb} / \mathrm{ft}^{2}$, and $\delta_{L E / T E}=5 / 10$. Boundary-layer profiles not shown because flow was separated. 

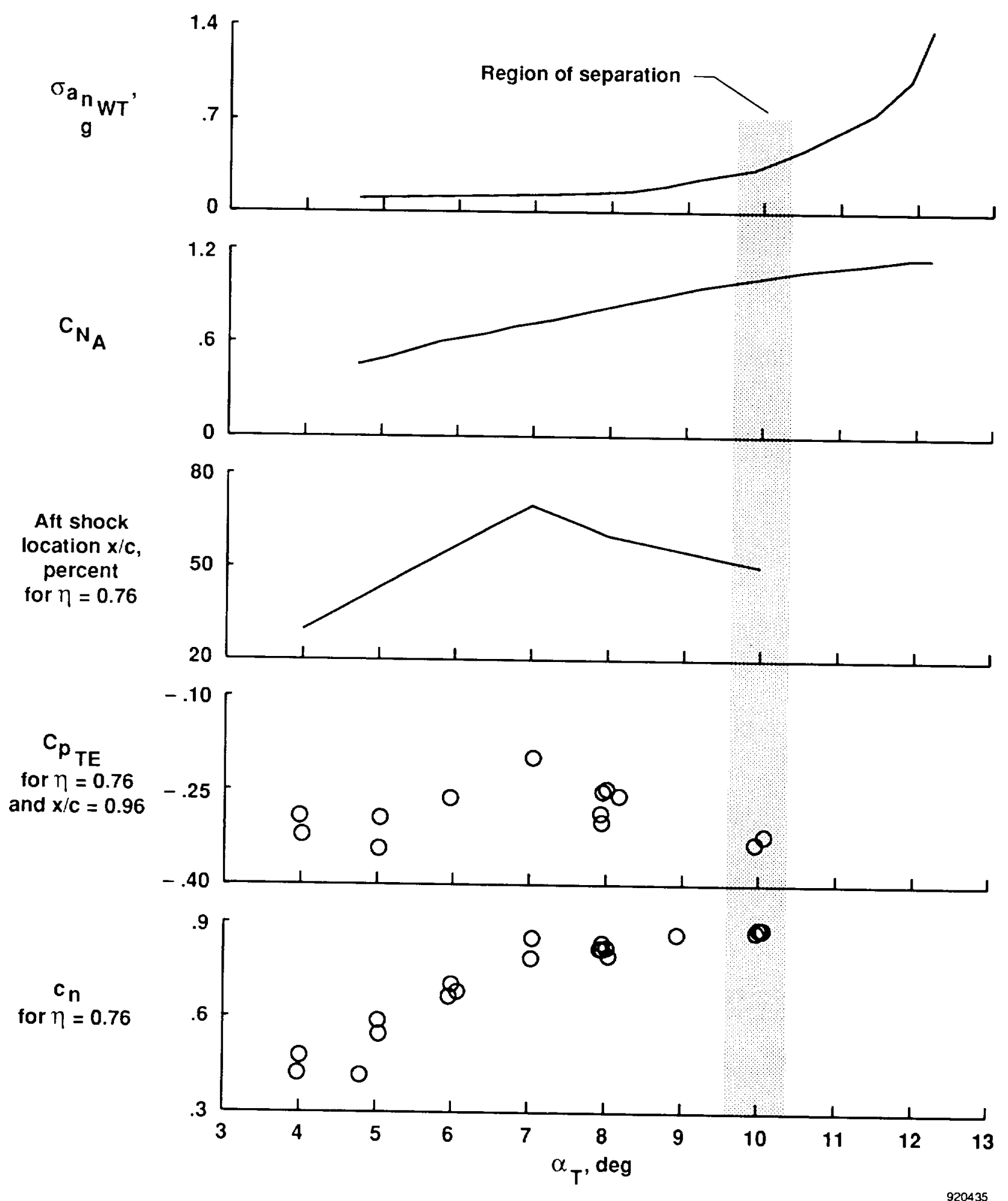

(d) Summary of breakpoints for pressure- and buffet-derived quantities.

Fig. 11 Concluded. 

Public reponing burden tor thic collection of intormation is estimaled to average 1 hour por response. Including the time lor reviewing instructions, searching oxisting data sources.

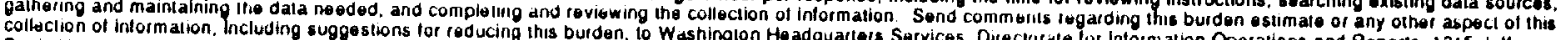

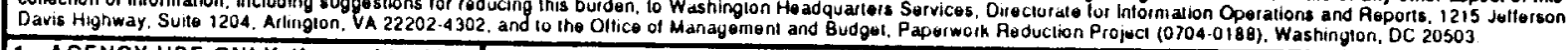

\begin{tabular}{|l|l|l}
\hline 1. AGENCY USE ONLY (Leave blank) & 2. REPOAT DATE & 3. REPORT TYPE AND DATES COVERED
\end{tabular}

\begin{tabular}{|l|l|l}
\hline 4. TITLE AND SUBTITE & November 1992 & Teclanical Memoramdum
\end{tabular}

5. FUNDING NUMBEAS

Flight Test Resulls From a Supercrilical Mission Adaptive Wing Will

Smooth Variable Camber

6. AUTHOR(S)

WU 533-02-11

Sheryll Goecke Power's, Lannie D. Webb, Edward L. Fitend, and Willian A. Lokos

7. PERFORMING ORGANIZATION NAME(S) AND ADDRESSIES)

NASA Dryden Flight Rescarch Facility

P.O. Box 273

Edwards, CA 93523-0273

8. PERFORMING ORGANIZATION

REPORT NUMBER

H-1855

9. SPONSORING/MONITORING AGENCY NAME(S) AND ADDRESS(ES)

10. SPONSORING/MONITORING AGENCY REPORT NUMBER

National Aeronautics and Space Administration

Wasthington, DC 20546-(x)1

NASA TM-4415

11. SUPPLEMENTARY NOTES

Prepared as AlAA-92-4101 for presentalion al the AlAA 6ul Biennial Flight lest Conference, Hilton Head, South Carolina, Augusi 24-26, 1992.

\begin{tabular}{|l|l|}
\hline 12a. DISTRIBUTION/AVAILABILITY STATEMENT & 12b. DISTRIBUTION CODE \\
Unclassilied - Unlimiled & \\
Subjecl Calegory 05 & \\
\hline 13. ABSTRACT (Maximum 200 words) & \\
\hline
\end{tabular}

The mission adaptive wing (MAW) consisted of leading-and trailing-edge variable-camber surfaces that could be deflected in flight to provide a near-ideal wing camber shape for any llight condition. These surfaces leatured smooth, hexible upper surlaces and fully enclosed lower surfaces, distinguishing them from conventional hlaps that have discontinuous surfaces and exposed or semiexposed mechanisms. Cannber shape was controlled by either a manual or automatic flight control system. The wing and airerali were exlensively instrumented to evaluate the local tlow characteristics and the total aircrafi performance. This paper discusses the interrelationships between the wing pressure, bulfel, boundary-layer and flight deflection measurement system analyses and describes the thight maneuvers used to obtain the data. The results are for a wing sweep of $26^{\circ}$, a Mach number of 0.85 , leading-and trailing-edge cambers $\left(\delta_{f \text { fert }}\right)$ of $0 / 2$ and $5 / 10$, and angles of attack from $3.0^{\circ}$ to $14.0^{\circ}$. For the well-behaved llow of the $\delta_{\text {IX/TE }}=0 / 2$ camber, a typical cruise camber shape, the local and global data are in good agreement with respect to the flow properties of the wing. For the $\delta_{t \in / L}=5 / 10$ camber, a maneuvering camber shape, the local and global data have similar trends and conclusions, but not the clear-cut agreement observed for cruise camber.

14. SUBJECT TERMS

AFIl/F-111 mission adaptive wing; Boundary-layer profiles; Smooth variable-camber wing; Wing buffel intensily; Wing pressures; Wing twist

\begin{tabular}{|c|c|c|c|}
\hline $\begin{array}{l}\text { 17. SECUAITY CLASSIFICATION } \\
\text { OF REPORT } \\
\text { Unclassilicd }\end{array}$ & $\begin{array}{l}\text { 18. SECUAITY CLASSIFICATION } \\
\text { OF THIS PAGE } \\
\text { Unclissilicd }\end{array}$ & $\begin{array}{l}\text { 19. SECURITY CLASSIFICATION } \\
\text { OF ABSTRACT }\end{array}$ & 20. LIMITATION OF ABSTAACT \\
\hline
\end{tabular}

